\title{
LA PESCA ENTRE LOS CAZADORES RECOLECTORES TERRESTRES DE LA ISLA GRANDE DE TIERRA DEL FUEGO, DESDE LA PREHISTORIA A TIEMPOS ETNOGRÁFICOS
}

\author{
JIMENA TORRES E:
}

\begin{abstract}
RESUMEN
El siguiente trabajo es una aproximación al desarrollo de las estrategias de pesca utilizadas por los grupos cazadores recolectores terrestres del norte de Tierra del Fuego, desde alrededor de los 5000 años AP hasta la llegada de los foráneos. La aproximación se hace a través de las evidencias arqueológicas -tecnología e ictioarqueología- y las fuentes etnográficas. Los resultados permiten constatar momentos de la importancia de la pesca en la subsistencia, además de variaciones en los modos de explotación, los cuales están evidenciados por los cambios tecnológicos y por la configuración de los conjuntos ictioarqueológicos desde el Holoceno medio hasta el periodo indígena-histórico. También se constata la presencia de campamentos especializados en esta actividad hacia los 2300 años AP y otros más tardíos donde su rol es similar al de los demás recursos marinos y terrestres. Por último, la presencia de corrales de pesca en la costa norte de Tierra del Fuego, permite discutir la permanencia y difusión de tradiciones tecnológicas a través del tiempo y espacio, en la extensa área de los archipiélagos septentrionales y meridionales.
\end{abstract}

PALABRAS CLAVES: estrategias de pesca, Tierra del Fuego, ictioarquología, tecnología de pesca, etnografía.

\section{FISHING AMONG TERRESTRIAL HUNTER GATHERERS OF TIERRA DEL FUEGO MAIN ISLAND, FROM PREHISTORY TO ETHNOGRAPHIC TIMES}

\section{ABSTRACT}

This paper examines the development of fishing strategies by terrestrial hunter-gatherers in northern Tierra del Fuego between 5000 BP and recent times. To do so, archaeological data (technology and fish bones) and ethnographic sources related to fishing practice are assessed. Analysis of this evidence reveals different moments in which the importance of fishing increases as well as some variability in the modes of exploitation. The study also detects the presence of specialized fishing camps dated to around $2300 \mathrm{BP}$ and later times, their position coherent with other marine and terrestrial resources. The paper 
discusses the presence of fishing corrals in the northern coast of Tierra del Fuego and highlights the permanence and diffusion of technological traditions through time and space in the broad area comprised by the northern and southern archipelagos.

KEY WORD: fishing strategies, Tierra del Fuego, ictioarchaeology, fishing technology, ethnography.

\section{INTRODUCCIÓN}

El interés en esta esfera del modo de vida de los cazadores terrestres de Tierra del Fuego, se debe en parte a que son escasos los trabajos que hayan profundizado en esta problemática, a excepción de los estudios ictioarqueológicos realizados en la vertiente atlántica de la isla (Campan 1992, Campan y Manzi 2000) y algunos del estrecho de Magallanes (Massone y Torres 2004, Torres 2006). La importancia de integrar esta clase de estudios en la arqueología de la región, radica en la necesidad de conocer y dimensionar la complejidad de los asentamientos litorales, abordando evidencias de fauna marina y tecnológicas de explotación de estos recursos, las que no siempre son vistas como diagnósticas o informativas del modo de vida cazador recolector terrestre.

Las investigaciones por lo general sostienen el supuesto tácito o explícito de la caza especializada del guanaco como un eje central en la planificación del sistema de asentamiento, la movilidad y duración de los campamentos residenciales; en cambio los demás recursos se ven como secundarios o complementarios en la dieta. De todas formas, si bien el guanaco presentó una mayor jerarquía en la subsistencia de estos cazadores, como se menciona en documentos etnográficos (Gusinde 1982, Chapman 1982, 1989; Coiazzi 1997, Gallardo 1998, entre otros) y en las investigaciones arqueológicas realizadas en el área (Borrero 1991, Massone et al. 1993), la heterogeneidad de ambientes y recursos entre la costa y el interior, como también entre los ambientes septentrionales y meridionales de la isla, generó variaciones en la forma de planificar temporalmente las actividades de subsistencia. Lo anterior se relaciona con las respuestas tecnológicas empleadas y las variaciones temporales en la organización socioeconómica. Los espacios costeros y sus recursos presentan una dinámica particular y distinta a los ambientes interiores, de esta manera los cazadores al conocer y anticipar estas variaciones, pudieron emprender un cambio transitorio de la jerarquía de ciertos recursos, como puede ser el caso de la ictiofauna.

Con el tiempo se ha incrementado la cantidad de trabajos enfocados en la importancia de los espacios y recursos costeros para los cazadores terrestres de Tierra del Fuego (Stuart 1977, Borrero 1985, 1991, Massone 1997, Morello et al. 1999, Morello y San Román 2000, Salemme y Bujalesky 2000, Morello et al. 2004, Massone et al. 2003, Massone y Torres 2004, Horwitz 2004). También ha aumentado en estos últimos años la investigación en la costa sureste de Tierra del Fuego, (Lanata 1993, 1996; Borella 2000), especialmente ha aumentado la información de ocupaciones de adaptación litoral de los últimos 1500 años, y también hay contextos entre los 5100 y 4300 años AP (Zangrando et al. 2008). Queda claro que las actividades vinculadas a la explotación y consumo de peces, son vistas como un tema menor y poco explicativo de problemas no económicos o de escala mayor como intercambio o cambio cultural, diferenciación sociocultural. No obstante, muchos de los datos reunidos aportan información acerca de algún tipo de vínculo entre poblaciones de la isla grande de Tierra del Fuego, los archipiélagos y el continente en distintos periodos. Nos referiremos principalmente al período comprendido entre los 2500 años AP hasta momentos etnográficos, ya que la mayoría de los datos se concentran en este rango temporal. No obstante también las evidencias retroceden a ocupaciones vinculadas al Holoceno medio (ca. 5000 años AP).

\section{COSTA SUR DEL ESTRECHO DE MAGALLANES}

En las ocupaciones más tempranas de este estudio, ya se habían producido los cambios ambientales que determinaron el aislamiento de Tierra del Fuego y en gran medida los procesos 
morfogenéticos que definieron las macro unidades geomorfológicas del paisaje. El área del estrecho de Magallanes está dentro de la provincia Magallánica o Patagónica, que se extiende por el Pacífico hasta el paralelo $52^{\circ} \mathrm{S}$ y por el Atlántico hasta los $53^{\circ}$ S. Esta provincia se encuentra subdividida en 5 distritos, siendo en el distrito fueguino en donde se ubica el área de estudio (Lloris y Rucabado 1991). El estrecho de Magallanes y el cabo de Hornos (56은 presentan afinidad de especies compuestas en su gran mayoría por especies subantárticas y endémicas (op. cit).

Particularmente, el estrecho de Magallanes está constituido por masas de aguas provenientes de tres océanos, el Pacífico, el Atlántico y mar de Drake con una salinidad superficial que varía entre $30,6 \%$ y $31,1 \%$ y una To entre $6^{\circ}$ y $7^{\circ}$ C. Estas últimas medidas corresponden a estudios realizados en la boca oriental del estrecho de Magallanes (Ríos et al. 2003). Por su parte, en este cuerpo de agua las ondas de marea son el agente hidrodinámico más significativo, la fuerte acción de las corrientes mareales generadas durante el día, en especial la generada por las olas de marea semidiurnas que vienen de las corrientes del atlántico, permite que la salinidad sea verticalmente homogénea como resultado de una rápida mezcla (op. cit). Las varia-

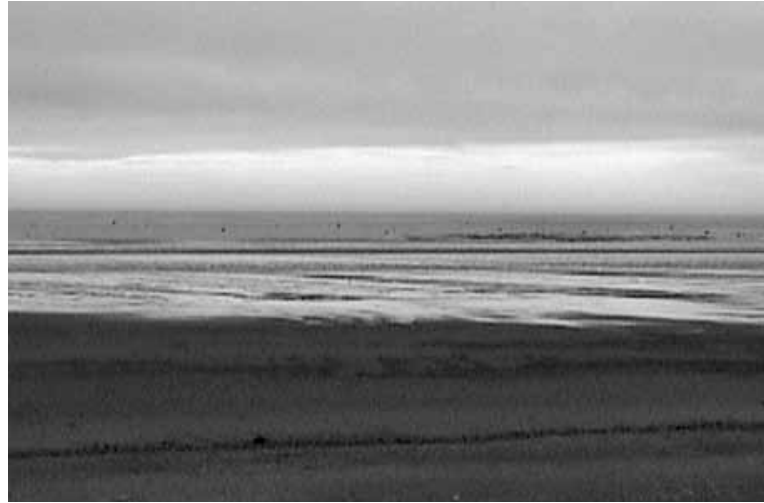

Fig. 1. Baja marea en bahía Lomas, noreste de la isla grande de Tierra del Fuego.

ciones de las condiciones abióticas y bióticas de los micro ambientes litorales inciden indiscutiblemente sobre la distribución, abundancia y diversidad de recursos ictiológicos litorales. Las entidades físicas del ambiente que, por lo general, son más importantes son la salinidad, la temperatura, la profundidad, desembocaduras de ríos, topografía, estructura de los sedimentos, corrientes oceánicas, sistema de mareas y oxigenación del agua, entre otros factores.

La baja inclinación de las playas principalmente en bahía Lomas (Fig. 1 y 2) y en el suroeste de bahía Inútil, en el sector de Cameron, influye significati-

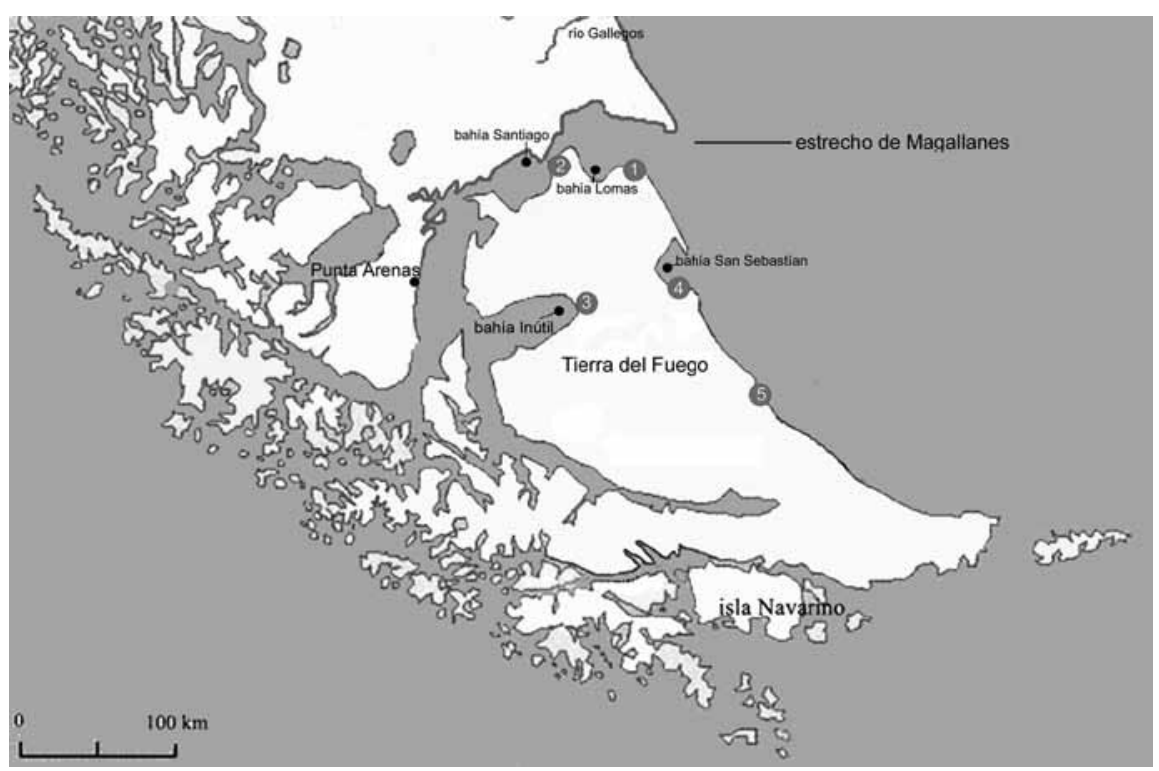

Fig. 2. Area de estudio; contextos de cazadores terrestres con evidencias de tecnología de pesca y/o restos de peces en Tierra del Fuego. 1) sitio Punta Catalina 3; 2) sitio Punta Baxa 7; 3) sitios Marazzi 1 - 2 - 30 - 32 y 38; 4) sitios San Genaro 1-2-3; 5) sitio Punta María 2. 
vamente en la amplitud de marea, permitiendo que con un leve cambio en la marea, se descubran o despejen amplias planicies intermareales. Esto se presenta tanto en punta Catalina, Segunda Angostura, como en el fondo de bahía Inútil; sectores donde se encuentran los sitios estudiados. Las playas abiertas, si bien exhiben menor biodiversidad a diferencia de ambientes con un intermareal rocoso, de todos modos producen situaciones ventajosas en función de los varamientos masivos de peces. Las especies gregarias que frecuentan este ambiente son el pejerrey (Odontesthes sp.), específicamente en remansos de aguas someras y en desembocaduras de riachuelos; y entre octubre y marzo aparece la merluza de cola (M. magellanicus) (Lloris y Rucabado 1991). El taxón predominante es el róbalo (Eleginops maclovinus), el cual es una especie residente de este ambiente bentónico litoral.

Una característica general de la costa del estrecho de Magallanes es la presencia de un hábitat litoral de bloques y de cantos, que definen las áreas desglaciadas y sectores amplios de costa (Ríos y Guzmán 1982, Ríos y Gerdes 1997). Este ambiente resulta más estable que los ambientes arenosos, principalmente por el tamaño de los sedimentos que lo componen y determinan una menor frecuencia de disturbios físicos (Ríos y Gerdes 1997). En la localidad de Marazzi, el tipo de sedimento varía desde rodados de 40-50 cm hasta playas de arenas gruesas; estas condiciones generan un ambiente propicio para el desarrollo de fauna bentónica litoral. También se ha señalado que este sustrato se presenta inestable, especialmente en la zona inferior del intermareal, por la perturbación que ocasiona el volcamiento de los clastos (Ríos y Guzmán 1982). Destacamos la presencia de E. maclovinus en distintos fondos tanto arenosos, fangosos, de piedras y arena, por lo que no presentaría tanta sensibilidad a las turbaciones del sustrato; asimismo muestra su tolerancia a los cambios de temperatura (López et al. 1996). Esta especie de ambiente bentónico litoral, especialmente estuarino, vive pululando a baja profundidad (0-5 $\mathrm{m}$ de prof.) y desova en pozos de marea de arenas gruesas, forma concavidades lenticulares de pocos centímetros y poca profundidad (Guzmán y Campodónico 1973, Lloris y Rucabado 1991). Esto también se extiende a la familia Zoarcidae que vive comúnmente en ambientes intermareales. En el caso de Austrolycus sp., vive bajo las piedras de la zona intermareal (Lloris y Rucabado 1991). Este sustrato, más la leve angularidad de la pendiente, permite la formación de pozones en bajamarea, como en las cercanías del poblado de Cameron, que pueden ser aprovechados para la construcción de corrales de pesca.

Las zonas intermareales representan una rica fuente de alimento y refugio para una amplia variedad de organismos, los cuales deben soportar frecuentes e importantes fluctuaciones ambientales tanto diarias como estacionalmente. Característicamente, la ictiofauna de esta zona está compuesta por especies residentes y especies transitorias. Los peces intermareales residentes están constituidos mayoritariamente por especies bentónicas las que pasan toda su vida en este ambiente, mientras que las especies transitorias visitan la zona intermareal principalmente en períodos de marea alta y en épocas reproductivas. Sin embargo habitan la mayor parte de su ciclo vital en la zona submareal (Quijada y Cáceres 2000). Existen además especies transitorias que ocupan la zona intermareal sólo en una etapa de su vida, frecuentemente como juveniles, por lo que estos ambientes se consideran como importantes zonas de reclutamiento para algunas especies (op. cit.)

\section{MATERIALES Y MÉTODO}

\section{Datos ictioarqueológicos}

Se consideraron los conjuntos ictioarqueológicos de sitios arqueológicos del litoral del estrecho de Magallanes (Fig. 2). Para la identificación taxonómica y de unidades anatómicas, se utilizó una colección osteológica comparativa. La identificación se basó en los elementos esqueletales diagnósticos (Colley 1990, Wheeler y Jones 1989). Se aplicaron las unidades de cuantificación básicas en los estudios zooarqueológicos; el NISP (Casteel y Grayson 1977, Grayson 1984) y NMI (Casteel y Grayson 1977). Para la cuantificación se seleccionaron las partes esqueletales más representativas de cada taxón, individuales (p.e. $1^{\circ}$ vértebra y basioccipital) o pareados (premaxilas, maxila, cuadrados, articulares y dentario), en este último se utilizó el criterio de lateralidad. Para evaluar la distribución de tamaños y peso se utilizaron las ecuaciones de las regresiones de elemento esqueletario/longitud estándar 
( $p=0,05)$, basándonos en el trabajo de Meléndez y colaboradores (1992). Sólo se aplicó a la muestra de E. maclovinus en todos los sitios, ya que es el único taxón que presenta una muestra significativa de unidades anatómicas y en los distintos sitios. La distribución de talla se basó en la estimación del MNI por medio de la abundancia de elementos y la longitud estándar sacada de la pieza más representativa (Torres 2006). El grado de confianza requerido fue $\mathrm{P}>.850$.

También se consideró la tecnología de pesca del sitio PC-3, PB-7 y de la localidad de Marazzi (MA-30, MA-1B y MA 1/sector 4). En general sólo esta representada por guijarros con escotaduras, surco o semisurco lateral (Torres 2007b). La demás información de tecnología proviene de estudios de otros investigadores de colecciones etnográficas (Prieto 2004) y de antecedentes entregados por investigadores en sitios arqueológicos de la vertiente atlántica.

\section{Etnografía}

Las fuentes escritas estudiadas provienen de observaciones sobre el modo de vida indígena, hechas por funcionarios de gobierno, misioneros salesianos y anglicanos, etnógrafos y crónicas de tripulantes de naufragio. El foco de atención de la información etnográfica se ciñe a las siguientes variables:

- Las características de las áreas de captación disponibles (estuarios, roqueríos, playas abiertas, ríos, corriente).

- El rango de especies explotadas.

- Los requerimientos de hábitat de las especies (p.e. condiciones pelágicas, bentónicas, demersales, sustrato rocoso, arenoso, grava-conchillas, pozones de marea).

- Comportamiento de los taxa (p.e. patrón migratorio estacional, gregariedad).

- Distribución y abundancia espacial.

- La importancia de los peces en comparación a los demás recursos y otras variables del consumo.

- Importancia estacional o en determinado eventos de ocupación litoral.

- Estrategia de captura, planificación, oportunismo, uso de tecnologías especializadas (masivas $\mathrm{o}$ individuales).

\section{RESULTADOS: LA PESCA ENTRE CAZADORES RECOLECTORES TERRESTRES DE TIERRA DEL FUEGO}

La información disponible sobre los selk'nam del norte, es considerablemente menor a la disponible de los cazadores terrestres del sur de Tierra del Fuego. Además, el cambio en el modo de vida tras la llegada de los europeos, genera la necesidad de recurrir a la arqueología como medio para indagar en el pasado inmediato al arribo de estas poblaciones. Pese a haber sido sometidos a un cambio abrupto en su forma de vida, preservaron gran parte de sus tradiciones y conocimientos sobre el medioambiente. No obstante, también entraron en desuso algunas estrategias al no tener acceso a ciertos espacios y recursos; por consiguiente los datos arqueológicos y etnográficos pueden utilizarse como instrumentos de contrastación sobre las continuidades y discontinuidades de determinados aspectos del modo de vida cazador recolector terrestre.

\section{Datos etnográficos sobre la importancia} de los recursos ictiológicos

Coiazzi (1997:54), sacerdote que convivió con los selk'nam del sur en 1910, dentro de sus observaciones señala que se aventuraban a la pesca en ocasiones donde la baja marea lo permitía. Menciona que había lugares donde los cambios de marea alcanzaban hasta más de dos kilómetros de extensión producto del leve declive de las playas en su proceso de retirada. Así, el mar va dejando charcos, escollos y piedras con moluscos y peces, incluso, de considerables dimensiones. También observa que en los equinoccios, el mar alcanza niveles de 6 a 7 metros sobre el nivel del mar.

A. Chapman (1982:46), menciona que para la pesca costera las mujeres mataban los peces con pequeñas lanzas o simplemente esperaban la bajamar y recogían con la mano los peces que hubieran quedado atrapados en charcos o en las rocas. Las observaciones son coincidentes con las de Coiazzi (1997), en especial en cuanto a las implicancias de los cambios de marea y la captura de los peces que quedaban atrapados. Igualmente C. Gallardo (1998:203) menciona sobre los selk'nam del norte, que a falta de tácticas especializadas para el aprovechamiento de peces prefieren recoger los que varan 
en las playas o se estancan en los pozos o rocas. Gusinde (1982:269) también realiza observaciones similares e indica que en la costa oriental del norte de Tierra del Fuego, el nivel del mar desciende muy gradualmente, lo que permite que en las bajamareas, las aguas se puedan retirar hasta dos kilómetros, $y$ en los charcos remanentes se pueden encontrar peces pequeños bajo las piedras. Según Gusinde (op. cit.) y relacionado con lo señalado por Chapman (1989:151), la tarea de la captura sería una labor propia de mujeres y niñas.

C. Gallardo menciona la importancia del consumo de peces en los grupos selk nam del norte, nombra en orden de importancia: [...]pescados, pájaros, cururos, lobo, guanaco, zorros, frutillas del campo,... y para los grupos del este, señala: [...]lobos, pescados mariscos, guanacos, pajaros, huevos,... (Gallardo 1998:171). También Gallardo, realiza una descripción y clasificación taxonómica de los recursos disponibles y especies ictiológicas aprovechadas por los selk'nam en ríos, lagunas y en el litoral. Menciona la presencia de trucha en los ríos, arroyos y lagos, y la define como Percichthys laevis; destaca la baja diversidad de especies en estos ambientes. En cuanto a los recursos ictiológicos del mar, señala que son abundantes, incluso, se refiere a casos excepcionales donde un lance de red puede sacar hasta tres mil peces de hasta 3 kilos cada uno (¿9 toneladas?) (Gallardo 1998:79). En términos de abundancia y propiedades de la carne para el consumo humano, destaca el róbalo (Eleginops maclovinus) por ambas cualidades, y la merluza común (Merluccius gayi) y el congrio colorado (Genypterus chilensis) por su tamaño, pese a no ser tan abundante. Es importante considerar que la especie Genypterus chilensis no es un taxón de aguas australes, sin embargo, si lo es el Genypterus blacodes o congrio dorado. Gallardo (1998:80), se refiere al congrio como abadejo, nombre que en la actualidad se le da al congrio dorado. También la mención a la merluza común (Merluccius gayi) se opone con la distribución actual de esta especie. La merluza de cola (Macruronus magellanicus), merluza del sur o común (Merluccius hubbsi) o merluza austral (Merluccius australis) son taxa que se distribuyen en el estrecho de Magallanes, costa atlántica y canal Beagle (Lloris y Rucabado 1991, Venegas y Sielfeld 1998). Lo más probable es que la discordancia de la identificación taxonómica se deba sólo a la imprecisión de la identificación de las especies observadas etnográficamente, y no a una variación en la distribución geográfica de ciertos taxa.

El mismo autor menciona el avistamiento de cardúmenes de pejerreyes y sardinas que varan en la playa, así como sus depredadores, el escobro y el haleche, los que tienen el mismo destino por ir tras éstos, y que pudieron eventualmente ser aprovechados para su consumo (Gallardo 1998:78). Probablemente una de estas dos especies depredadoras es la merluza de cola (Macruronus magellanicus), taxón que en la actualidad se registra en depósitos naturales en bahía Inútil al norte de Tierra del Fuego, y que vara durante los meses de verano, especialmente en enero. Por lo general, esta especie se acerca a las aguas litorales desde octubre hasta marzo (Lloris y Rucabado 1991). En otros sectores como el canal Beagle se han observado varamientos de cientos de merluzas de cola con sardinas en sus estómagos y bocas (Zangrando 2003). El resto de los meses del año esta especie es poco frecuente y su disponibilidad cerca de la costa también disminuye. Otra especie mencionada por Gallardo (1998:80) es el pejerrey que

Tabla 1. Contexto de las muestras estudiadas.

\begin{tabular}{|c|c|c|c|c|}
\hline \multirow{4}{*}{$\begin{array}{l}\text { Sureste del } \\
\text { estrecho de } \\
\text { Magallanes }\end{array}$} & Sitio & Estrato & Datación & Referencias de los sitios \\
\hline & PB-7 & IV & $1.210 \pm 40$ años AP (Beta-201496) & \multirow{2}{*}{ Morello et al. 2005} \\
\hline & PB-7 & VI & $1.360 \pm 40$ años AP (Beta-201497) & \\
\hline & PC-3 & II & $\begin{array}{l}2.340 \pm 40 \text { años AP. (Beta 187978) } \\
2.380 \pm 40 \text { años AP (Beta 187977) }\end{array}$ & Massone y Torres 2004 \\
\hline \multirow{5}{*}{$\begin{array}{l}\text { Noroeste del } \\
\text { estrecho de } \\
\text { Magallanes }\end{array}$} & MA-32 & I & $\begin{array}{l}635 \pm 35 \text { años AP. (Ua-21184). } \\
560 \pm 35 \text { años AP. (Ua-21185. }\end{array}$ & $\begin{array}{c}\text { Massone et al. 2003, } \\
\text { Massone y Morello 2005 }\end{array}$ \\
\hline & MA-38 & II & $\begin{array}{l}795 \pm 35 \text { años AP. (Ua-21182). } \\
785 \pm 35 \text { años AP. (Ua-21183) }\end{array}$ & Massone et al. 2003 \\
\hline & MA-2 pozo $25 \mathrm{~N} / 35 \mathrm{E}$ & $\mathrm{C}$ & $1.965 \pm 40$ años AP (Ua-21140) & \multirow{2}{*}{ Morello et al. 2004} \\
\hline & MA-2 pozo $90 \mathrm{~N} / 1 \mathrm{E}$ & $\mathrm{E}$ & $2.745 \pm 40$ años AP (Ua-21141) & \\
\hline & Marazzi 1 & Medio & $\begin{array}{c}5.440 \pm 30(\text { Beta- TF25-125315) } \\
5.570 \pm 400 \mathrm{AP}\end{array}$ & $\begin{array}{l}\text { Morello et al. 1999; Laming- } \\
\text { Emperaire 1968, } 1972\end{array}$ \\
\hline
\end{tabular}


se acerca a la costa en cardúmenes, concentrándose en las desembocaduras de ríos, donde se mezcla el agua dulce y el agua salada del mar.

Por lo general, las fuentes etnográficas hablan de un uso secundario de los recursos malacológicos e ictiológicos. Sus estrategias de consumo se vinculan con los recursos que habitan en el intermareal o los que se acercan al litoral en determinadas épocas del año. Chapman (1982:46) menciona que el consumo de recursos marinos en general siempre se encuentra en un segundo plano dentro de la dieta de los indígenas. Se consumía en casos de urgencia o simplemente por un deseo de variar la dieta (Chapman 1989:142). Esta autora señala que los peces más nombrados eran: róbalos, truchas, congrios, anguilas, peces de piedra, pejerrey, sardinas; de los cuales el primero era el más apreciado (Chapman 1982:46). En esto coincide con Gallardo (1998:80), quien destaca al róbalo como un pez valorado por los selk'nam. También se señala que durante los meses de verano y principios de otoño los selk'nam consumen grandes peces sin escamas llamados dehapiu, que quedan atrapados entre las rocas de la playa (Mayorga 1972). Estos podrían ser congrios (Genypterus sp) o también algún tipo de zoárcido como el genero Austrolycus sp. (morena).

Datos arqueológicos de consumo de fauna ictiológica

Las evidencias ictioarqueológica corresponden a sitios arqueológicos ubicados en el estrecho de Magallanes. Hay un conjunto de sitios en bahía Inútil, localidad de Marazzi. Los sitios son Marazzi 32, Marazzi 38 y Marazzi 1 (Tabla 1). Más hacia el sur en la misma bahía está el sitio Marazzi 2, al costado del río Torcido. Al sureste del estrecho de Magallanes se encuentra el sitio Punta Baxa 7 en la Primera Angostura, y más hacia el extremo este del estrecho, está el sitio Punta Catalina 3 en la punta homónima.
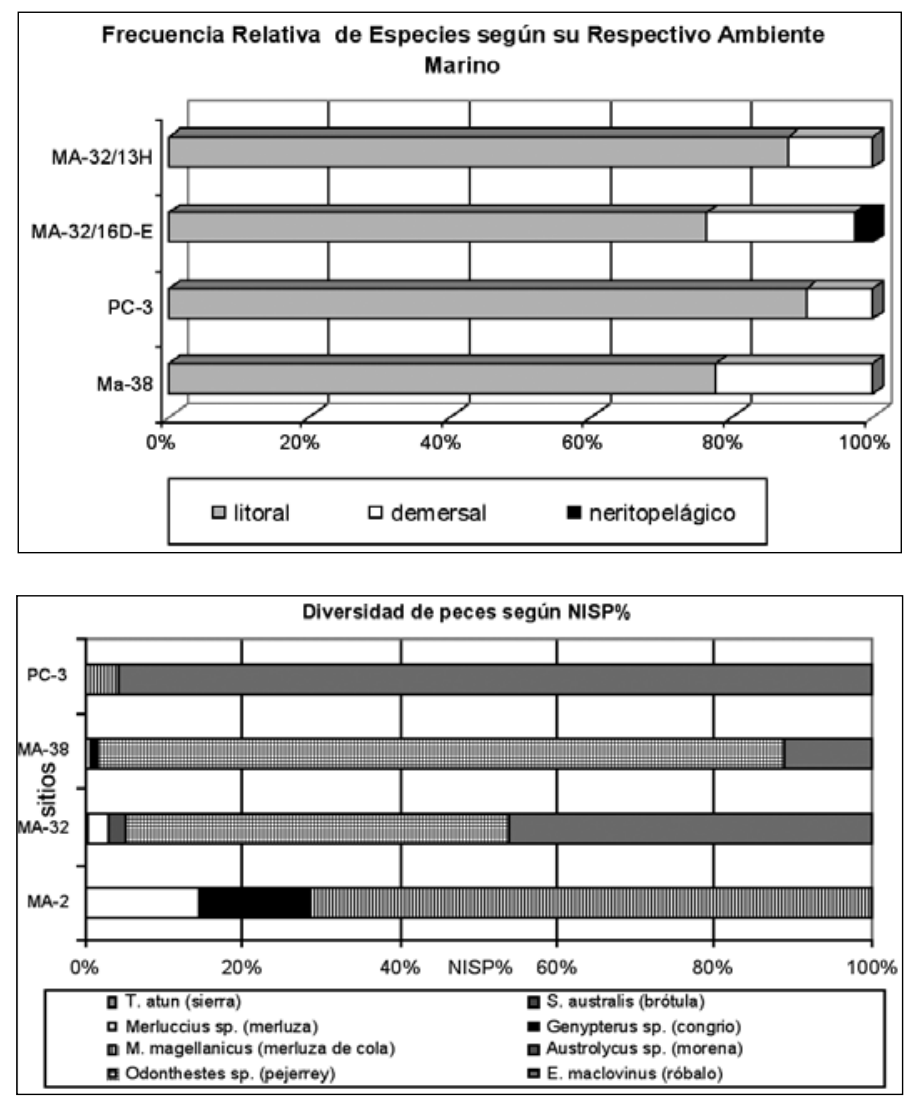

Fig. 3. Izquierda: Frecuencia relativa de peces según su ambiente marino. Sitio Ma32, PC-3 y Ma-38. Derecha: diversidad de especies por sitio arqueológico. 
Tabla 2. Abundancia taxonómica de peces; sitios del estrecho de Magallanes, Tierra del Fuego.

\begin{tabular}{|c|c|c|c|c|c|c|c|c|c|c|c|c|c|c|}
\hline \multirow[b]{3}{*}{ Taxón } & \multirow{2}{*}{\multicolumn{2}{|c|}{$\frac{\text { Ma-32 }}{16 \mathrm{D}-\mathrm{E}}$}} & \multirow{2}{*}{\multicolumn{2}{|c|}{$\frac{\text { Ma- } 32}{13 \mathrm{H}}$}} & \multicolumn{2}{|c|}{ Ma-38 } & \multicolumn{2}{|c|}{ Ma-2 } & \multirow{2}{*}{\multicolumn{2}{|c|}{$\begin{array}{c}\text { Ma-1 } \\
\begin{array}{l}\text { medio/ } \\
\text { inferior }\end{array}\end{array}$}} & \multicolumn{2}{|c|}{ PB-7 } & \multicolumn{2}{|c|}{ PC-3 } \\
\hline & & & & & \multirow[b]{2}{*}{ 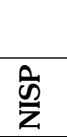 } & \multirow[b]{2}{*}{$\sum_{\Sigma}$} & \multirow[b]{2}{*}{$\begin{array}{l}\text { जे } \\
\text { Z }\end{array}$} & \multirow[b]{2}{*}{$\sum$} & & & \multirow[b]{2}{*}{ 离 } & \multirow[b]{2}{*}{$\sum$} & \multirow[b]{2}{*}{ 离 } & \multirow[b]{2}{*}{$\sum_{\Sigma}^{\bar{Z}}$} \\
\hline & 离 & $\sum$ & $\frac{\hat{n}}{\mathbf{Z}}$ & $\sum_{\Sigma}^{\bar{z}}$ & & & & & जे & $\sum_{\Sigma}$ & & & & \\
\hline \multicolumn{15}{|l|}{ Especies litorales } \\
\hline Odontesthes (pejerrey) & 586 & 12 & 11 & 3 & 16 & 4 & & & & & & & & \\
\hline E. maclovinus (róbalo) & 236 & 16 & 330 & 15 & 123 & 3 & & & 47 & 2 & 4 & 3 & 508 & 22 \\
\hline Austrolycus sp. (morena) & 7 & 1 & 21 & 4 & & & & & 7 & 1 & 7 & 3 & & \\
\hline \multicolumn{15}{|l|}{ Especies demersales o pelágicas } \\
\hline Merluccius sp. (merluza común) & 32 & 5 & & & 1 & 1 & 1 & 1 & 27 & 2 & 1 & 1 & & \\
\hline S. australis (brótula) & 1 & 1 & 1 & 1 & & & & & & & & & & \\
\hline S. capensis (cabrilla) & 6 & 2 & 11 & 2 & & & & & & & & & & \\
\hline T. atun (sierra) & 1 & 1 & & & & & & & & & & & & \\
\hline Macruronus magellanicus & & & & & & & 5 & 2 & & & & & 16 & 2 \\
\hline Genypterus sp. (congrio) & & & & & 1 & 1 & 1 & 1 & & & & & & \\
\hline Total & 869 & 38 & 374 & 25 & 141 & 9 & 7 & 4 & 81 & 5 & 12 & 7 & 524 & 24 \\
\hline
\end{tabular}

Según la información obtenida de los sitios de Marazzi, río Torcido, Primera Angostura y Punta Catalina, hay un claro énfasis en la captura de especies residentes de ambientes bentónico litorales como es el E. maclovinus (róbalo) (Fig. 3, Tabla 2). Otro taxón que predomina es Odontesthes (pejerrey), si bien es un taxón pelágico litoral, se concentra generalmente en aguas someras, estuarios y en algunas bahías del norte de Tierra del Fuego. En contraste, las especies demersales y neríticas, es decir, de aguas más profundas o más distantes a la costa, forma una mínima parte del conjunto ictiofaunístico (Torres 2007a).

En la actualidad se observa mayor diversidad de especies en aguas someras del fondo de bahía Inútil, que en punta Catalina, esto concuerda con el registro arqueológico de ambos sectores. Marazzi 32 es uno de los sitios tardíos, con fechas cerca de los
500 y 600 años AP (Tabla 1), tiene alta diversidad y abundancia de especies, tanto de peces, como mamíferos terrestres, marinos y aves marinas (Fig. 4). Asimismo, la especie E. maclovinus muestra una distribución de talla dispersa sin una tendencia marcada, posiblemente por el tamaño de la muestra estudiada, aunque de todos modos esboza una distribución normal de la población, lo que refleja la captura de peces sin un criterio selectivo por talla (Fig. 5). Igualmente el sitio Marazzi 38 también presenta una cronología reciente, y en él predominan especies litorales, la más abundante es el pejerrey, bastante por debajo está el róbalo (Tabla 2). Las especies demersales y bentodemersales como Merluccius sp. (merluza) y Genypterus sp. (congrio), están escasamente representadas. Hay a lo menos dos taxa no identificadas que posteriormente se identificó una como Austrolycus sp.. El

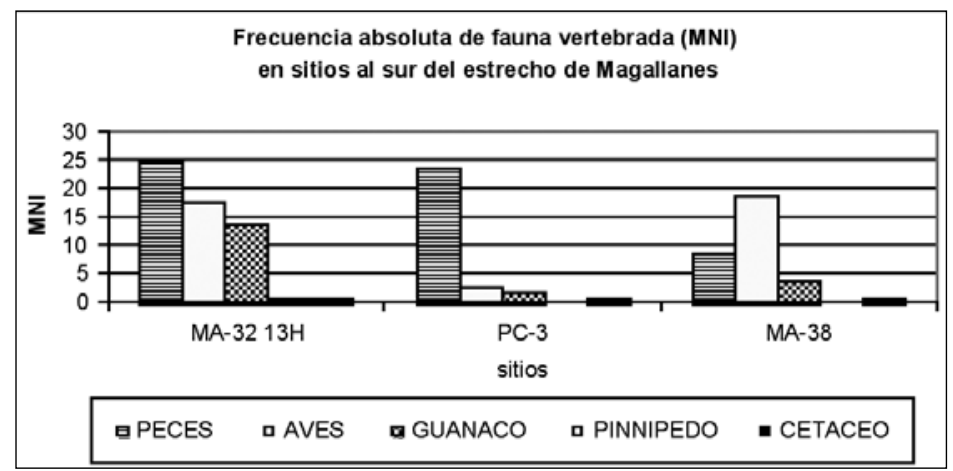

Fig. 4. Importancia de tipo de fauna vertebrada por sitio arqueológico del estrecho de Magallanes. 

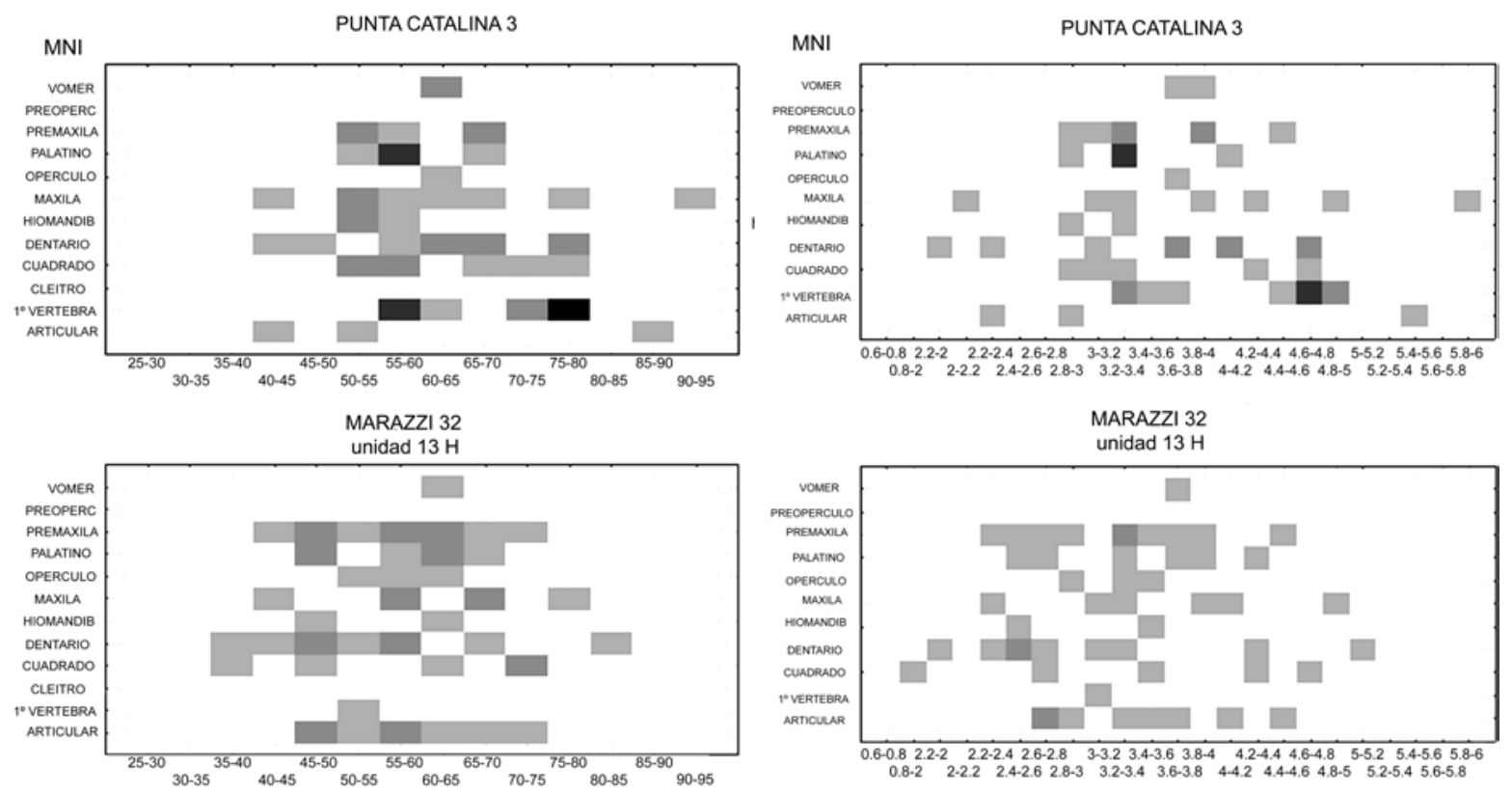

MARAZZI 32/ UNIDAD 16D-16E
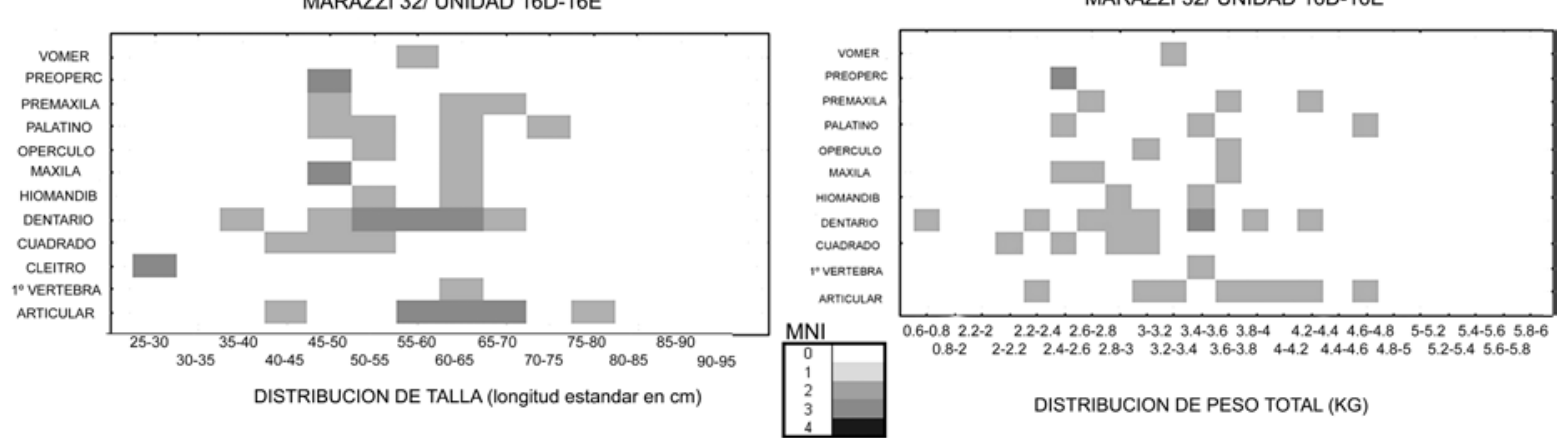

Fig. 5. Distribución de peso y talla (longitud estándar) de E. maclovinus, según el MNI de cada unidad anatómica. Sitios del estrecho de Magallanes.

sitio también presenta diversidad de aves marinas y de ictiofauna similar a Ma-32, con un predominio de peces litorales (Fig. 3 y 4).

En el sitio PC-3, uno de los más antiguos de la muestra, y el que presenta mayor densidad de restos de peces por $\mathrm{m}^{3}$, muestra un predominio absoluto de peces en comparación a mamíferos y aves (Torres 2007a, Massone y Torres 2004). El conjunto está constituido principalmente por róbalo; su abundancia es esperable, ya que actualmente es la especie litoral más abundante y explotada en este sector, a diferencia de otras zonas del estrecho de Magallanes, por el lado de Tierra del Fuego, en donde la pesca de orilla también incluye la captura de pejerrey (Odontesthes) y/o palometa (Stromateus sp).
Otra especie que aparece en PC-3, es Macruronus magellanicus (merluza de cola), pero tiene sólo una mínima representación. La presencia de este taxón podría sugerir el uso estival del asentamiento, ya que presenta un patrón migratorio estacional marcado, aproximándose en forma de cardúmenes a fines y comienzos de cada año (Lloris y Rucabado 1991). No obstante, sólo serviría de indicador en el caso que sean restos de origen cultural; este es un taxón muy común en contextos naturales del área, y no queda totalmente claro si es un depósito previo o posterior al suceso cultural.

En cuanto a los tamaños (longitud estándar), hay un predominio de individuos entre los $50 \mathrm{y}$ los $80 \mathrm{~cm}$ (Fig. 5). Concretamente hay dos rangos 
donde se encuentra la máxima concentración, uno entre 55-60 cm y otro entre $75-80 \mathrm{~cm}$. Por otro lado, se pudo estimar una distribución de peso total bimodal que fluctúa entre los $3,2-3,4 \mathrm{~kg}$ y otra entre los 4,6-4,8 kg. Pese a esta leve tendencia se observó una distribución amplia, entre los $2 \mathrm{~kg}$ y los $6 \mathrm{~kg}$ (op. cit.). Los tamaños se relacionan a individuos adultos que bordean las tallas más grandes de esta especie y si se considera que se requiere más de 8 años para que un individuo logre un tamaño de $79,7 \mathrm{~mm}$, indicaría que se capturaron individuos que bordean los 8 años de edad (CORFO-IFOP 1982). Probablemente la captura se realizó en zonas un poco más profundas, ya que según la distribución espacial y de profundidad por edad, los juveniles por lo general se concentran en desembocaduras y aguas someras; en cambio los adultos en aguas hasta los 5 $\mathrm{m}$ de profundidad. Según la información dada por pescadores artesanales la concentración de róbalos grandes se da principalmente en el verano, lo cual también podría dar indicios de estacionalidad. Se sabe que entre las especies que habitan las aguas someras del canal Beagle, E. maclovinus es uno de los que presenta mayor aporte en biomasa, presenta un peso máximo de $2,20 \mathrm{Kg}$. y un largo máximo de $60 \mathrm{~cm}$ (López et al. 1996). A este dato se suma que para esta misma área se señala un tamaño máximo de 30-32 cm de este taxón y que es superior a la talla de la demás ictiofauna de la zona (Moreno et al. 1984). Tomando en cuenta esta información, los ejemplares hallados en el contexto de PC-3 muestran una distribución de peso y talla bastante superior; incluso la mayoría se encuentran sobre los $2,8 \mathrm{~kg}$. de peso y principalmente entre $3,2-4,8 \mathrm{~kg}$, que en definitiva da cuenta de un significativo rendimiento económico.

Por otro lado está el sitio Marazzi 1 que es uno de los escasos contextos con fechas del Holoceno medio (5.570+/- 400 AP) y Holoceno temprano -de 9.590 AP- en Tierra del Fuego (Laming-Emperaire 1968, 1972). Además es el único contexto más antiguo con restos de fauna ictiológica. Reevaluaciones posteriores a fines de los 90' refuerzan la cronología concerniente al Holoceno medio (5440 \pm 30 años AP), sin embargo, deja abierta la discusión del depósito Holoceno temprano (Morello 1999, Morello et al. 1999). Los restos de peces analizados fueron recuperados en las investigaciones posteriores a los de la misión francesa, la estratigrafía estaba parcialmente revuelta, tanto por procesos naturales (madrigueras), como por la misma remoción de sedimento generada en las excavaciones anteriores (Morello et al. 1999). En este estudio sólo fueron considerados los restos que se encontraban en una matriz clara y asignable al estrato medio (Holoceno medio) e inferior ( ${ }^{\mathrm{H}} \mathrm{Ho}-$ loceno temprano?) y se agruparon en una unidad única. Al igual que en los demás contextos, el róbalo es la especie más representada, lo que demuestra su disponibilidad en este sector, a lo largo de los últimos 5000 años. Otra especie importante en Ma-1 es la merluza común (Merluccius sp.), la cual en los otros contextos aparece secundariamente. Su presencia podría significar una explotación estacional, por sus acercamientos a la costa en el período estival; además en la actualidad en bahía Inútil, esta especie se presenta escasamente en ambientes de orilla, aún en el verano. Por último hay escasos restos de morena (Austrolycus sp.) y de una especie pequeña no determinada taxonómicamente, es posible que sea alguna especie de la familia Nothoteniidae. En este contexto, por el momento, no hay un estudio integrado de la importancia de estos recursos en relación a la demás fauna vertebrada ${ }^{2}$, no obstante la presencia de peces indicaría una explotación bastante antigua por parte cazadores terrestres. Es difícil establecer si este recurso se encuentra en este período dentro de un patrón de subsistencia recurrente, ya que los sitios con estas fechas son escasos y no hay otro que presente este tipo de fauna.

El énfasis en la explotación del róbalo pudo tener relación con la riqueza de este recurso, traducible en biomasa, aporte en lípidos y proteínas. Sumado a esto está su fácil captura, abundancia, concentración y predictibilidad a lo largo de todo el año en el ambiente de orilla. Una estrategia planificada con o sin tecnología especializada masiva (redes), es decir aprovechando las bajas mareas para atrapar los peces atrapados en los pozones, son estrategias que acrecientan su optimización dada la disponibilidad natural. Asimismo, la conjunción de estos aspectos permitirían una ocupación más prolongada o sino con mayor cantidad de personas, más aún si se ocupa una tecnología de captura masiva como en el sitio Punta Catalina 3. El sitio costero Punta Baxa 7 (PB-7) muestra un bajo rol de este recurso; hay escasos restos de peces y en

2 Tesis de pregrado de Elisa Calás en curso. 
una amplia y profunda excavación, hay restos de róbalo, merluza común y morena, pero denota el uso de tecnologías especializada de pesca (quizás líneas de pesca). En síntesis, PC-3, PB-7 y MA-1 son los contextos más tempranos junto a Marazzi 2 y se observa una baja diversidad de ictiofauna. En PC-3 hay una especificidad en la explotación de peces pasando a un segundo plano la demás fauna vertebrada. En cambio en los sitios de bahía Inútil -localidad de Marazzi- hay una diversidad bastante mayor de fauna vertebrada, como de fauna ictiológica de ambientes demersales y bentónicos litorales. Se han hecho los intentos de encontrar evidencias de explotación de peces en sitios de ambientes interiores, para evaluar transporte de peces desde la costa al interior y evidencias, de pesca en ambientes dulceacuícolas, no obstante no se ha hallado ningún tipo de información (Torres 2007a).

Según la información en sitios de la vertiente atlántica, el sitio San Genaro 1 tiene un predominio de especies demersales como Merluccius hubbsi (merluza común) y Macruronus magellanicus (merluza de cola), y bentodemersales como el Genypterus blacodes (congrio dorado) (Campan y Piacentino 2004). También aparecen representados restos de Odontesthes (pejerrey), Cottoperca Gobio (torito de los canales) y restos de la clase Chondrichthyes (peces cartilaginosos). En este contexto los restos de peces predominan en comparación a los demás conjuntos zooarqueológicos y en menor medida los pinnípedos. Presenta un conjunto de fechados que abarca desde el $610 \pm 45,1.070 \pm 80,1.190 \pm 90,1.479 \pm 95$ y $1.620 \pm 140$, lo que implicaría la reocupación de estos asentamientos en un rango de 1000 años. También se interpreta como un campamento de estrategias generalizadas donde se da una relación total entre los recursos disponibles y los recursos consumidos (Horwitz 2004). No obstante, al considerar el estudio de Campan y Piacentino (2004), donde se estima un MNI de 22 ejemplares de peces y una abundancia de NISP que supera lo mencionado por Horwitz (2004) para los taxa como guanaco (Lama guanicoe), zorro colorado (Pseudalopex culpaeus), pingüino (Spheniscus sp.) y pinnípedos, reconsidera la importancia de la actividad de pesca y la caza de pinnípedos en el sitio. En cambio para los sitios San Genaro 2 se observa un predominio de guanaco y pinnípedo, y en menor medida, aves, peces y roedores (Horwitz 2004). Por otro lado Punta María 2
(1.230 \pm 50 años) también muestra un predominio del consumo de guanaco y pinnípedo y en menor medida aves, peces y cetáceos (Borrero 1985). En este sitio la presencia de una secuencia temporal prolongada, indica una reutilización del espacio de manera de una sucesión de eventos cortos dirigidos a la obtención y consumo de recursos inmediatos (op. cit.). No obstante, pese a observarse una estrategia que indica actividades de explotación generalizada o predadora, el énfasis en determinados taxa supone una especificidad en las funciones del campamento $y$, en alguna medida, el uso de estrategias dirigidas y planificadas hacia un recurso.

\section{Estacionalidad de los sitios arqueológicos con evidencias de pesca}

En el sitio Punta Catalina 3 la presencia de $M$. magellanicus indicaría que posiblemente la estación de captura de esta fauna fue en los meses estivales. Esto por el patrón migratorio marcado que tiene este taxón y su acercamiento en los meses de verano, principalmente enero (LLoris Rucabado 1991). No obstante está la duda si se tratarían de restos previos al depósito arqueológico o posterior a éste. Junto a esto está la asociación a restos de individuos juveniles de Lama guanicoe (Massone y Torres 2004), que refuerzan la idea del uso del campamento a comienzo de verano. En cuanto a la distribución de talla de Eleginops maclovinus como indicador de estacionalidad, se observa que en PC-3 -independiente de la selectividad dada culturalmente-; la captura de tallas grandes pudo estar determinada por la estructura poblacional en un determinado periodo del año. Un estudio realizado en la desembocadura del río Bueno en la Región de los Lagos, indica que la mayor concentración y mayores tamaños de E. maclovinus se da en el mes de abril (Arcos 2002). Por otro lado R. Konig $(1996)^{3}$, a partir del estudio de la composición física y química de la misma especie, observa que tanto el peso, la longitud y el perímetro de los ejemplares es mayor en primavera y es considerablemente menor en otoño, lo que difiere con los trabajos antes mencionados. Además señala para este período un mayor peso de las vísceras en verano y en menor

3 Las muestras fueron obtenidas de pescadores artesanales de la isla de Mancera, provincia de Valdivia (Región de Lagos, Chile) (Konig 1996). 
medida en primavera, aunque de todas maneras alto. En cambio, en invierno los individuos mostraron un peso inferior de sus vísceras (op. cit.). En cuanto a la variación estacional del aporte de lípidos y proteínas del róbalo, se plantea que hay una variación significativa, los lípidos varían de acuerdo a las épocas de restricción alimentaria (invierno) y por su ciclo reproductivo con un desove a fines de invierno $e$ inicios de primavera en adelante. De esta manera el valor más alto de lípidos lo presenta en otoño, en invierno baja debido a la escasez de alimentos y al desove, y en primavera los lípidos llegan al mínimo observado, luego en verano la alimentación aumenta y comienzan acumular lípidos (op. cit.). En la actualidad los pescadores artesanales de punta Catalina señalan que entre diciembre y marzo, y en especial enero, es el período de mayor productividad de este recurso, tanto por su abundancia como por su tamaño. Si las condiciones ambientales actuales son similares a los momentos de la ocupación prehistórica, posiblemente los eventos de captura fueron durante meses estivales, por el gran tamaño de los ejemplares arqueológicos. $\mathrm{Si}$ se da una preferencia estacional en la captura y consumo por su aporte en grasas, posiblemente el otoño y el verano fueron las estaciones ventajosas. En cuanto al aporte proteico, no presenta variaciones estacionales significativas aunque se encuentra fuertemente relacionado con los contenidos de lípidos, presentando los mayores y menores valores en las mismas estaciones. De esta manera en el caso de privilegiar presas de mayor tamaño se optaría por una pesca entre la primavera y el verano, y en caso de optar por un mayor aporte en lípidos y proteínas se realizaría una pesca preferentemente en verano $u$ otoño y nunca en meses invernales.

Respecto a MA-32, las evidencias de un uso estival podrían estar en la unidad $13 \mathrm{H}$ con 12 individuos juveniles de L. guanicoe muy pequeños con no más de 3 meses de edad, siendo en su mayoría ejemplares de alrededor de un mes; los adultos son sólo 2 y de tamaños similares (Prieto y Martin 2005). Las unidades 16D y 16E también presentan ejemplares juveniles y neonatos. En el sitio Marazzi 1 la presencia significativa de Merluccius sp, indicaría ocupaciones de uso estival en el caso que fuese una pesca de orilla, no obstante al utilizar embarcaciones, es posible su acercamiento a zonas de pesca de merluza en otras épocas del año. En el sitio Punta María 2 , vertiente atlántica de Tierra del Fuego, a partir del análisis del crecimiento de vértebras se observó que la captura de los distintos peces se llevó a cabo tanto en verano como en invierno (Campan 1992). En general, considerando todos los indicadores de estacionalidad planteados, los datos indican una tendencia al uso estival de los campamentos, no obstante, falta mayor resolución y explorar nuevos indicadores para establecer de manera específica y segura la veracidad de las interpretaciones.

\section{TECNOLOGÍA Y TÁCTICAS DE PESCA}

Por lo general, se señala que los selk'nam aprovechaban los peces que quedaban atrapados o se escondían en pozos, charcos, piedras o entre el barro del intermareal (Coiazzi 1997, Gallardo 1998, Chapman 1982, 1989). Incluso, se menciona que los selk'nam del norte tenían más dificultades para la pesca que los del sur, por lo que preferían recoger los peces que quedaban varados (Gallardo 1998:203). Sin embargo, se aluden tácticas formales que incluyen tecnologías tanto expeditivas como de mayor formatización y especialización. No sólo estaba la organización tecnológica o tácticas de pesca, sino la organización social de las actividades según edad y género; esto se encontraba estrechamente relacionado con quienes realizarían determinadas actividades asociadas a la pesca.

Uso de lanzas, palos aguzados, azagayas $y$ arpones

Algunos de los implementos de pesca, especialmente usados por las mujeres selk'nam del sur, eran las cestas, lanzas y arpones, en los charcos que deja la baja marea (Chapman 1982:46, 1989:151). Con el mango del arpón se levantaban las piedras y con la punta se ensartaba al pez arrojándolo al cesto (Coiazzi 1997:54). Esta observación del uso de arpones es escasa y confusa. Gallardo (1998:203), menciona el uso de un pequeño arpón con punta dentada de hueso con el cual pescan en pozos de poca profundidad o entre las piedras. Gusinde (1982:269), también alude el uso de un arpón, es decir, una punta de hueso con un sólo diente, la que es utilizada por mujeres y niñas para pescar en los charcos de marea. Lothrop (1928) también menciona el uso de un arpón pequeño para estos fines, incluso muestra un ejemplar similar a los hallados arqueológicamente. 

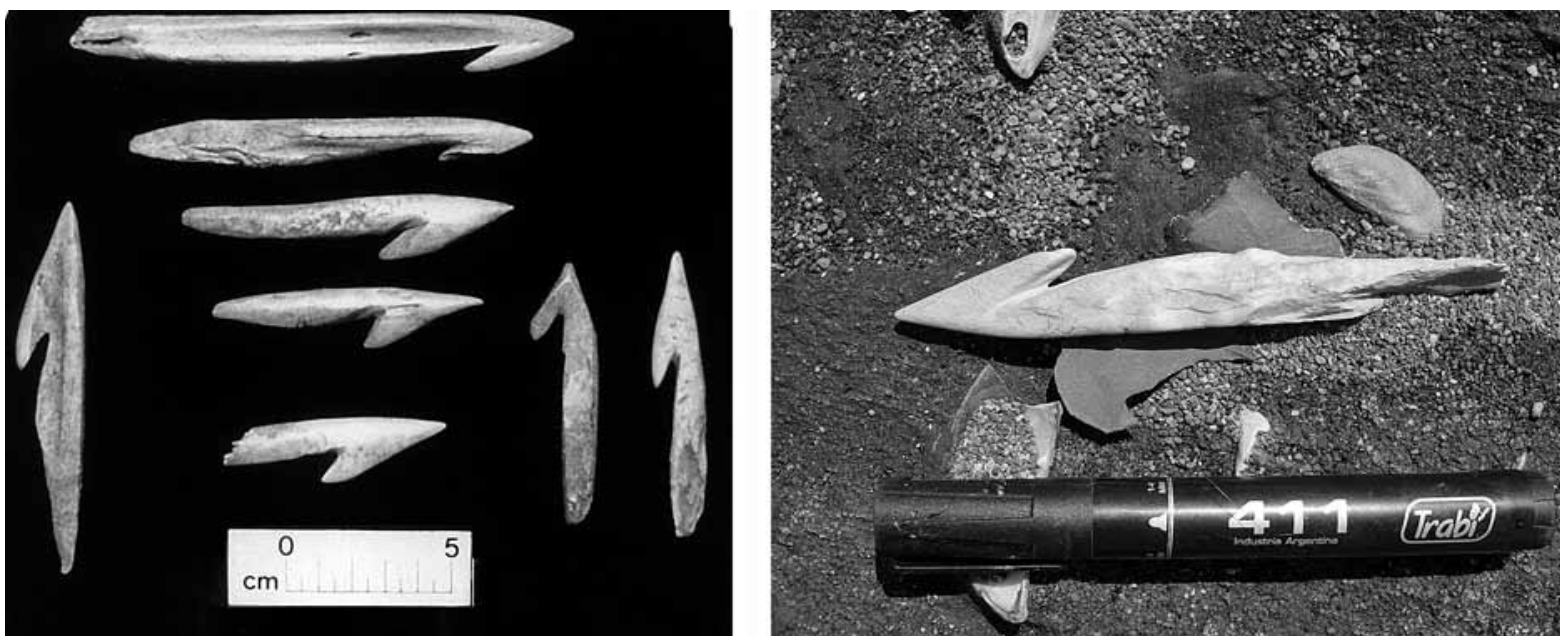

Fig. 6. Izquierda: Puntas en metapodios de Lama guanicoe, sitio Punta María 2, costa central de la vertiente atlántica de Tierra del Fuego (foto: Luis Borrero). Derecha: Punta en metapodio de Lama guanicoe, Sitio San Genaro 3, (foto: Karen Borrazzo).

En los grupos canoeros kawésqar, el uso de arpones en hueso de ballena está destinado principalmente a la caza de delfines, pinnípedos y nutrias, y sólo en ocasiones a la pesca de grandes peces (Emperaire 1963, Vega 1995). Bridges (2000:93), destaca la habilidad de los yámanas con el arpón para pescar, desde la proa de la canoa capturaban peces de tamaño similar o mayor a los salmones, los que se encuentran a buena distancia de la superficie. Los grupos de adaptación marina usaron arpones con punta separables y fijas multidentadas, probablemente los utilizaron con mayor eficacia en lugares de mayor profundidad y desde embarcaciones. Según los relatos, si los grupos selk'nam del sur ocuparon esta tecnología, debió ser un arpón menos complejo que aquel usado por los canoeros o más bien una punta ósea con una barba y enmangue fijo.

Los arpones compuestos tienen una composición más compleja, y su uso se relaciona con la pesca de peces de mayor tamaño o de mamíferos marinos como pinnípedos. Un arpón se puede definir morfológicamente como puntas con barbas sobre uno o dos bordes, con un extremo distal generalmente vulnerable (punta aguda) y una extremo proximal plano o afinado que permita la inserción o la fijación en un astil, puede tener diversos accesorios destinados a la fijación de una línea (como escotadura o protuberancias) (Bellier et al. 1995). Estos últimos atributos o accesorios se encuentran presentes en arpones con bases más complejas.

\section{Arpones y/o puntas óseas arqueológicas}

Por el momento la única información arqueológica sobre el uso de puntas óseas en cazadores terrestres de Tierra del Fuego, está en el sitio Punta María 2 en la desembocadura del río Fuego y en el sitio San Genaro 3, en bahía San Sebastián, todos en la vertiente atlántica de Tierra de Fuego (Fig. 6). Las piezas fueron manufacturadas sobre metapodios de guanaco, tienen extremo distal monodentado y el extremo proximal simple. Destaca la proporción del largo de la espiga en comparación al largo del fuste, este último es bastante más prolongado, además de presentar una extracción prolongada (cuña) en la base en dirección a la parte medial del fuste aprovechando en algunos casos la misma cavidad medular. Esto posiblemente se relaciona con su enmangue fijo en un astil, por lo que sería una punta ósea de arma de mano o una lanza arrojadiza a mano. Para aclarar esto sería necesario un estudio de su mecánica de funcionamiento más detallado. El contexto PM-2 no muestran ninguna asociación y proximidad especial, la temporalidad se acerca a los últimos 300 años radiocarbónicos (com. pers. Borrero 2009). Sólo en la base de las secuencias, pre 1.300 AP, hay cierta delimitación espacial clara; hay peces, aves, pinnípedos y guanacos, estos dos últimos más o menos en partes iguales (comp. pers Borrero 2009).

Las puntas óseas del sitio San Genaro 3, en la localidad Chorrillos sur de la bahía San Sebastian, 


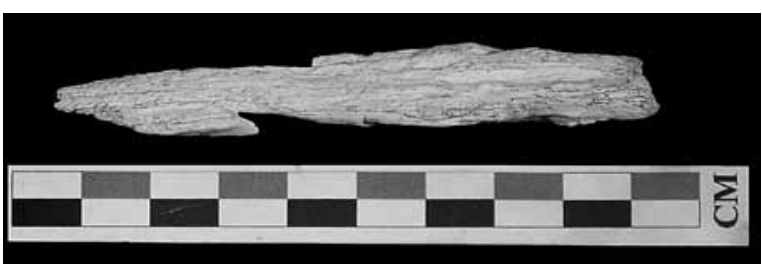

Fig. 7. Punta ósea recolección superficial, Bahía Santiago, estrecho de Magallanes.

norte de Tierra del Fuego, son mayoritariamente hallazgos superficiales. Los fechados más cercanos a los depósitos que presentaban estas piezas son 680 \pm 60 años AP (LP-1774- carbón-) y $990 \pm 70$ años AP (LP-2075 -valvas- corregido por reservorio: 590 \pm 70 años AP). Estas serían fechas máximas para los depósitos que contienen las piezas (com. pers. Borrero 2009).

En la costa sur del estrecho de Magallanes, por el momento, no hay piezas similares en contextos arqueológicos; no obstante, como antecedente relevante, está el hallazgo superficial de una punta ósea en bahía Santiago en el sector continental del estrecho de Magallanes, aproximadamente frente a Segunda Angostura (Fig. 7). Esta pieza es similar a las descritas para la vertiente atlántica de Tierra del Fuego, también se encuentra manufacturada en metapodio de guanaco y posiblemente, por la localización del hallazgo, corresponde a un instrumento de filiación cazador recolector terrestre continental ${ }^{4}$. Con respecto a otros antecedentes de Patagonia continental en la provincia de Chubut, Argentina, hay estudios en los lagos de la cuenca del lago Musters, que mencionan referencias de trabajos anteriores donde señalan la presencia de arpones hechos en huesos de mamíferos terrestres (Moreno et al. 2007). No obstante, estos han sido interpretados como destinados a la captura de nutrias o coipos (Myocastor coypus) (Gómez Otero et al.1998:147). También, se mencionan la presencia de colecciones arqueológicas de guijarros con muescas que podrían ser pesos de pesca, los cuales fueron hallados en esta cuenca lacustre, además de abundantes restos de peces asociados a fogones (Moreno et al. 2007).

En el caso de los hallazgos asociados a cazadores terrestres de Tierra del Fuego, tienden a

4 La recuperación de este instrumento fue realizada por el señor Hans Roehrs, y con posterioridad fue donada al Centro de Estudios del Hombre Austral, Instituto de la Patagonia, Universidad de Magallanes. vincularse a contextos posteriores a los $1.000 \mathrm{AP}$ y a contextos aún más recientes, alrededor de los 500 años AP. Por el momento se puede plantear a modo de hipótesis que es una tecnología utilizada en tiempos tardíos por los cazadores terrestres tanto del continente como de la costa atlántica de Tierra del Fuego, sur este de Tierra del Fuego, como en los sitios ubicados en Bahía Valentín en península Mitre (Zangrando et al. 2008). De todos modos también se debe considerar la influencia de grupos de adaptación marina del sureste y suroeste de Tierra del Fuego, en la incorporación y variaciones de esta tecnología.

\section{Uso de caña, cebo o líneas de pesca}

Es interesante la distinción que se hace respecto a los selk'nam del norte y del sur. Los primeros además de preferir peces que quedaban varados en las playas o encerrados entre las rocas o los pozones, también utilizaban técnicas de pesca individuales, como la caña o cebo (Gallardo 1998:203, Gusinde 1982:266). Gusinde, señala que algunos indígenas en diversas bahías y lagunas del norte de Tierra del Fuego pescaban con caña. Este modo consiste en un hilo largo atado a una vara larga y firme, en el extremo del hilo se ata un trozo de carne, el que hace la función de carnada que se sumerge en el agua, y cuando el pez coge el hilo, con un impulso se le saca a la superficie (Gusinde 1982:266). El autor no hace mención del uso de algún lastre para esta técnica. Para los indígenas del sureste de Tierra del Fuego hay menciones que señalan: [...]sus mugeres todas las baja (sic!) mares hiban á pescar con un palito muy flexible, en cuio extremo tienen una barba de ballena con su nudo corredisco, en el que ponen la carnada, y con esto pescan sin ansuelo... (Schindler 1995:183).

Por el momento sólo hay referencias para los grupos yámanas sobre el uso de piedras como lastres o pesas para líneas de pesca. Según Bridges (2000:94), una táctica propia de las mujeres era el uso de sedales hechos de su propio cabello trenzado. Cerca de la carnada ataban a la caña una piedra perfectamente redondeada con una pequeña ranura hecha ex profeso para sujetar la línea. El autor indica no haber visto nunca a los indígenas elaborar este tipo de piedras, ni escuchó que las hicieran en su época, por lo que piensa que probablemente gene- 
raciones anteriores debieron haberlas dejado en tal cantidad en las chozas abandonadas, que resultaba innecesario el enorme trabajo de tallar nuevas piedras (Bridges 2000:94-95). En otras fuentes escritas se nombran las características morfológicas de la pesa para su buen funcionamiento, señalándose que la piedra debe ser perfectamente redonda para hundirla con rapidez (Orquera y Piana 1999). Otro dato es el uso de diferentes tipos de pesas dependiendo de la línea utilizada. Los yámanas empleaban líneas de cochayuyo y líneas de tendones trenzados. Para esta última técnica se usaban guijarros con mayor peso y para el amarre les hacían dos escotaduras apicales (Lothrop 1928:159, Gusinde 1982:473 y 530). También se menciona el uso de piedras redondas con un surco alrededor de toda la pieza. Un dibujo de una línea de pesca recuperada por la Misión Científica del Cabo de Hornos (Colección del Museo del Hombre de París), muestra una larga trenza de tendones amarrada entorno a una piedra ovalada muy redondeada, además, se observa que las ranuras para sujetar la trenza se encuentran en la parte más larga de la pieza (Prieto y Cárdenas 2002). Las observaciones referentes a la forma ovalada de la pieza, las hendiduras en la parte más larga del guijarro y la redondez de la pieza para su rápido hundimiento, permiten aproximarnos a los requerimientos tecnológicos de una pesa de línea y diferenciarlas de las que tuvieron otros fines prácticos.

Uso de redes de pesca

La utilización de redes, a diferencia de las líneas de pesca, es prácticamente exclusiva de los grupos selk'nam y haush, ya que no hay datos de su uso por grupos de adaptación marítima. Incluso se señala que los últimos alacalufes (kawésqar) no recuerdan haber sabido o visto el uso de esta tecnología en tiempos pasados (Emperaire 1963:182). Existen coincidentes observaciones que asocian la pesca con red a las actividades de apropiación realizadas por los hombres, tal como la caza (Coiazzi 1997:54, Gallardo 1998:204, Gusinde 1982:268, Chapman 1989:151, Schindler 1995:184). En cambio, la pesca en bajamar con la mano o con pequeñas lanzas, se vincula a las actividades realizadas por mujeres (Chapman 1989). Igualmente las actividades de recolección y marisqueo eran hechas por mujeres, niños y ancianos, y al parecer cualquier actividad de apropiación más especializada correspondía al ámbito masculino. No obstante, hay una referencia aislada del uso por mujeres de líneas de pesca con nudo corredizo (Schindler 1995). Contrastan estas descripciones del vínculo de las mujeres canoeras con tácticas de apropiación especializadas y las de cazadoras terrestres con tecnologías especializadas; las primeras mujeres pescaban con líneas desde embarcaciones y buceaban para conseguir recursos del fondo, como moluscos y crustáceos (Orquera y Piana 1999).

Respecto a la confección de las redes, se señala que la confección era muy similar a la que utilizan los occidentales, incluso con el mismo nudo, pero el material para su confección; eran tendones de guanaco (Coiazzi 1997:54, Gallardo 1998:204, Chapman 1989:142). También se menciona el uso de barbas de ballena para su elaboración (Chapman 1989). Gallardo (1998: 204) señala que en la elaboración se requería de mucho trabajo e insumos -tendones-, razón por la que había muy pocos ejemplares de redes, prefiriéndose ramas para obstaculizar la huída de los peces al mar. Los tendones recién sacados son de unos $50 \mathrm{~cm}$; estos se pueden subdividir sacando muchos hilos de cada uno, que eran torcidos sobre el muslo para hacer una cuerda. El mismo autor menciona que las redes tenían una extensión de $10 \mathrm{~m}$ de largo, $1.5 \mathrm{~m}$ de ancho y mallas grandes (Tabla 3). Esto implicaba que para extender la red se requería de 6 a 10 hombres (op. cit). Según Coiazzi (1997) la extensión de la red era de $2 \mathrm{~m}$ de largo y, por lo menos, 1 metro de ancho, además se requerían 2 hombres para extenderla.

Tabla 3. Datos métricos de algunas redes descritas etnográficamente o en estudios de colecciones etnográficas.

\begin{tabular}{|c|c|c|c|}
\hline Largo & Ancho & $\mathbf{N}^{\circ}$ de hombres & Referencias \\
\hline $3 \mathrm{~m}$ arriba y $2,4 \mathrm{~m}$ abajo & $0,55 \mathrm{~m}$ & & Prieto 2004 Museo Salesiano Punta Arenas \\
\hline $1,5 \mathrm{~m}$ & $0,8 \mathrm{~m}$ & & Prieto 2004 (Museo del Hombre de París) \\
\hline $2 \mathrm{~m}$ & Menos de $1 \mathrm{~m}$ & 2 & Coiazzi 1997 \\
\hline $10 \mathrm{~m}$ & $1,5 \mathrm{~m}$ & $6 \mathrm{a} 10$ & Gallardo 1998 \\
\hline 8 a diez bras.os $(\mathrm{sic})$ & & 2 & Schindler 1995 \\
\hline
\end{tabular}


En cuanto a los datos sobre los grupos haush del sureste de Tierra del Fuego, Lista (1998:98) menciona sobre los onas de bahía Thetis el uso de pequeñas redes hechas de nervio de guanaco sin especificar donde se usaban (río-lagunas-mar) ni como se maniobraban. Este dato puede corresponder a los haush, ya que dicha bahía está dentro de sus limites geográficos (Lanata 1996). Otra referencia que alude a estos grupos es dada por los tripulantes del buque español llamado Nuestra Señora de la Concepción y que naufragó en 1764 en la costa

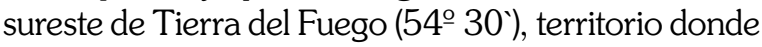
habitaban los haush (Schindler 1995). Describen lo siguiente [...]porque los hombres no mariscan, sino es para comer crudo sobre la marcha, pero estos tienen otro modo de pescar, que es en las Playas con unas redes de ocho á diez brasos muy bien hechas de tripas de animales torcidos, lo mismo que cuerdas de Bidon hechas á malla grande... (Schindler 1995:183). Sobre el modo de uso, continúan relatando: [...]Con esta red se meten dos yndios en el agua hasta el pescuezo, y después/149/ caminando para tierra de sacan buenos pezes... (Id. 1995:183). La red descrita pudo tener una longitud equivalente a brazas españolas ${ }^{5}$, si así fuese, sería la red de pesca más extensa descrita y su uso se vincula posiblemente a los grupos Haush del sureste de Tierra del Fuego. La manera de usar esta red podría ser similar, en algún grado, al tipo de red que hoy en día observamos que se utiliza en algunos sectores, como punta Catalina, para la pesca de róbalo, ya que se señala en esta referencia su uso en el mar y su manejo por sólo dos personas que la arrastran hasta la orilla. De esta manera su uso no depende decisivamente de la amplitud de marea, sino del arrastre de la red inmediatamente al llegar a una buena profundidad. En el caso de la utilización de redes de orilla con plomadas, lastres y algún tipo de elemento flotante, puede haber distintas modalidades del uso de la red. Esta no necesariamente se maniobra en la baja marea para su instalación o retiro, hay algunas que, en la actualidad, se pueden extender y retirar arrastrándolas a la orilla con cuerdas o un bote.

Sobre el modo de uso de redes, Gallardo señala que el procedimiento de captura consistía en caminar en el río o arroyo con la red extendida

5 Si se refiere a una braza española equivale a $1,6718 \mathrm{~m}$ y una braza inglesa a $1,8288 \mathrm{~m}$. en posición vertical contra la corriente, sujetada con las manos arriba y con el dedo mayor del pie en la parte inferior, mientras tanto, niños y mujeres ahuyentaban a los peces con ramas y piedras, obligándolos a dirigirse hacia la red (Gallardo 1998:204). Coiazzi señala que ante la cercanía de los peces, con los pies se tira la red hacia adelante, y la parte superior se tira con los brazos hacia abajo; una vez atrapado el pez, se arrojaba con la mano hacia fuera (Coiazzi 1997:204). Gusinde (1982:266) menciona que se esperaba que la marea alta llegara a su nivel máximo y que los peces pudieran internarse por la desembocadura de los ríos; se estiraba la red de orilla a orilla en el río o arroyo, sujetándose con los dedos del pie en la parte inferior y el borde superior con la mano izquierda, como también lo mencionan Coiazzi (1997) y Gallardo (1998). Con la red estira$\mathrm{da}$, se retomaba lentamente el río, portando en la mano derecha un garrote o varilla para empujar los peces hacia la red, los jóvenes, río arriba, revolvían o agitaban el agua, dirigiéndose hacia la red para que los peces se enfrentaran con ésta. También arrojaban piedras desde la orilla para los mismos fines. Cuando los peces quedaban atrapados en la red, un hombre los sacaba y los lanzaba a la orilla (Gusinde 1982: 266). Según A. Chapman (1989:151), con posterioridad a la captura, los peces se dividían entre los que realizaban la captura o sostenían la red y los que mataban los peces en la orilla del río. El ambiente donde se usaba la red era principalmente dulceacuícola como ríos, arroyos -en su sección más angosta- y en las desembocaduras de los mismos (Gusinde 1982, Chapman 1989, Coiazzi 1997, Gallardo 1998). Gusinde (1982:268), señala que al interior de Tierra del Fuego existen pocos lugares donde se pudo haberse aplicado esta técnica, e incluso en los lugares potenciales, es raro que se haya aprovechado.

Retomando lo anterior, la referencia de Schindler es una de las pocas referencias que hay sobre el uso de redes de pesca en ambientes costeros, las demás aluden a ambientes fluviales, lagunares o desembocaduras de ríos. Destaca los altos costos en la elaboración de esta tecnología, por lo que había pocos ejemplares; esto a diferencia de otras tecnologías especializadas y de alto grado de curaduría, como las puntas de proyectil para arcos y flecha, que si bien requiere de un conocimiento especializado en su manufactura, los costos en tiempo y materiales 


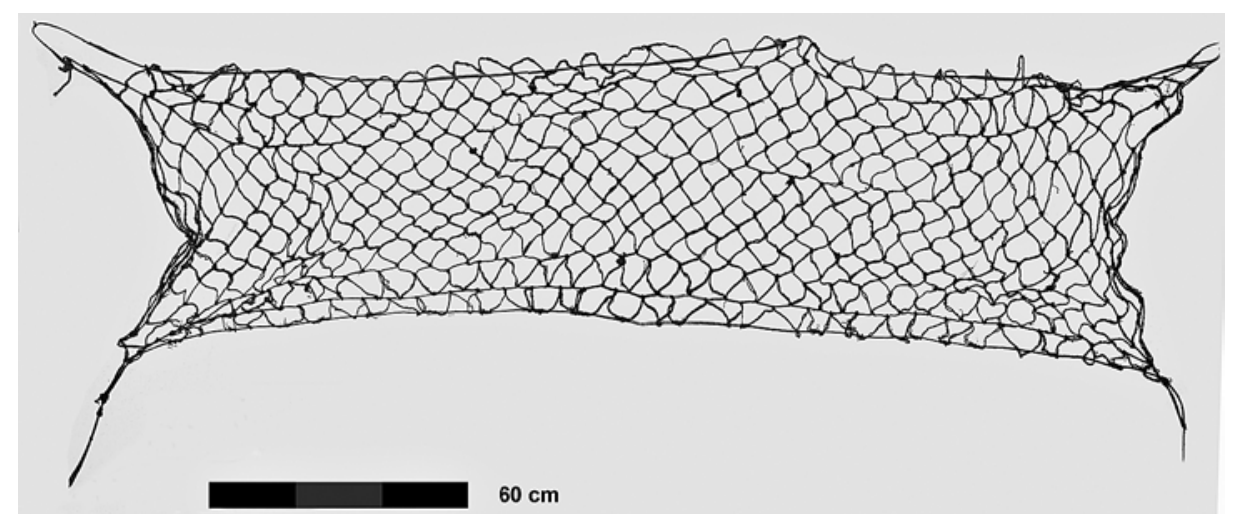

Fig. 8. Red de pesca del museo Salesiano Mayorino Borgatello, Punta Arenas. El registro oficial de colecciones del museo, indica: "red ona hecha de de nervios con una tira". Dice en forma difusa y poco legible: "indios de Tierra del Fuego". (Foto: Gabriel Bahamonde).

no son tan altos como en el caso de una red de pesca. Estos datos tecno-económicos dan cuenta del vínculo en estos conocimientos entre selk'nam y haush, pero la forma del uso de esta tecnología indica una orientación más costera en el caso de los haush. El uso de esta tecnología, pese a que se relaciona más a las actividades de procuramiento del hombre, da cuenta de una organización del trabajo en función de la captura, en donde participan los distintos integrantes del grupo, a diferencia de otras actividades de apropiación más individuales o relacionadas específicamente a mujeres u hombres, o a distintos grupos etarios.

Datos arqueológicos sobre redes y líneas de pesca en cazadores recolectores terrestres

Ante lo perecedero de las fibras orgánicas para la confección de redes y líneas de pesca, estas dos tecnologías sólo se han podido identificar arqueológicamente a partir de pesos líticos. Esto bajo el supuesto que se necesitase algún tipo de lastre, como ya se ha mencionado etnográficamente para los grupos canoeros con el uso de líneas de pesca. No obstante, en el caso de los cazadores terrestres de Tierra del Fuego no hay registro del uso de redes con lastres o algún sistema de flotación para la red. Hay pocos ejemplares de redes y/o datos más precisos de su confección y características. No obstante, la descripción cualitativa y métrica de la red selk'nam que se encuentra en el Museo Salesiano Mayorino Borgatello permite desprender algunas características funcionales de este arte de pesca
(Prieto 2004). La red estudiada mide $3 \mathrm{~m}$ de largo en su parte superior y 2,40 en la parte inferior y unos $55 \mathrm{~cm}$ de ancho (Fig. 8). Se compone de un tejido de cuerdas trenzadas diagonales que conforman rombos y tres largas cuerdas, tanto trenzadas, torcidas como crudas que corren dos arriba y una abajo (op. cit). Dos de ellas, las más externas tienen una suerte de lazo en sus extremos los que sirven para sujetar y contraer la red. Bajo la superior, que es trenzada, hay una cuerda simplemente torcida que corre paralela a esta y de la cual se sostiene la primera fila de rombos. Esta cuerda permite una pequeña contracción entre nudos ya que son corredizos. La de abajo es una lonja fina de cuero y debió soportar mayor tensión. Los rombos del entramado tienen 7 $\mathrm{cm} \times 8 \mathrm{~cm}$, los nudos de la red en sentido horizontal son distintos a los verticales, por lo menos en cuanto a su aspecto. Las tiras trenzadas están hecha de a dos hilos de tendones, por lo que puede tratarse de un sólo tendón dividido en dos (op. cit). Destaca la diferencia de esta red con las descritas por Gallardo y la del Museo del Hombre de Paris, esto por la ausencia de cuerdas en la parte inferior y superior que permita contraer la red y también reforzarla. Las lonjas de cuero menos elástica y más firme dan indicios del uso de algún elemento complementario (Prieto 2004). No obstante, es probable que sólo se trate de un refuerzo y no una aplicación para poner lastre, por lo que se trataría de una variación en el uso de redes (op. cit).

El sitio Punta Catalina 3, es un buen ejemplo del posible uso de redes con pesos líticos, quizás similar al que hoy usan los pescadores de orilla 


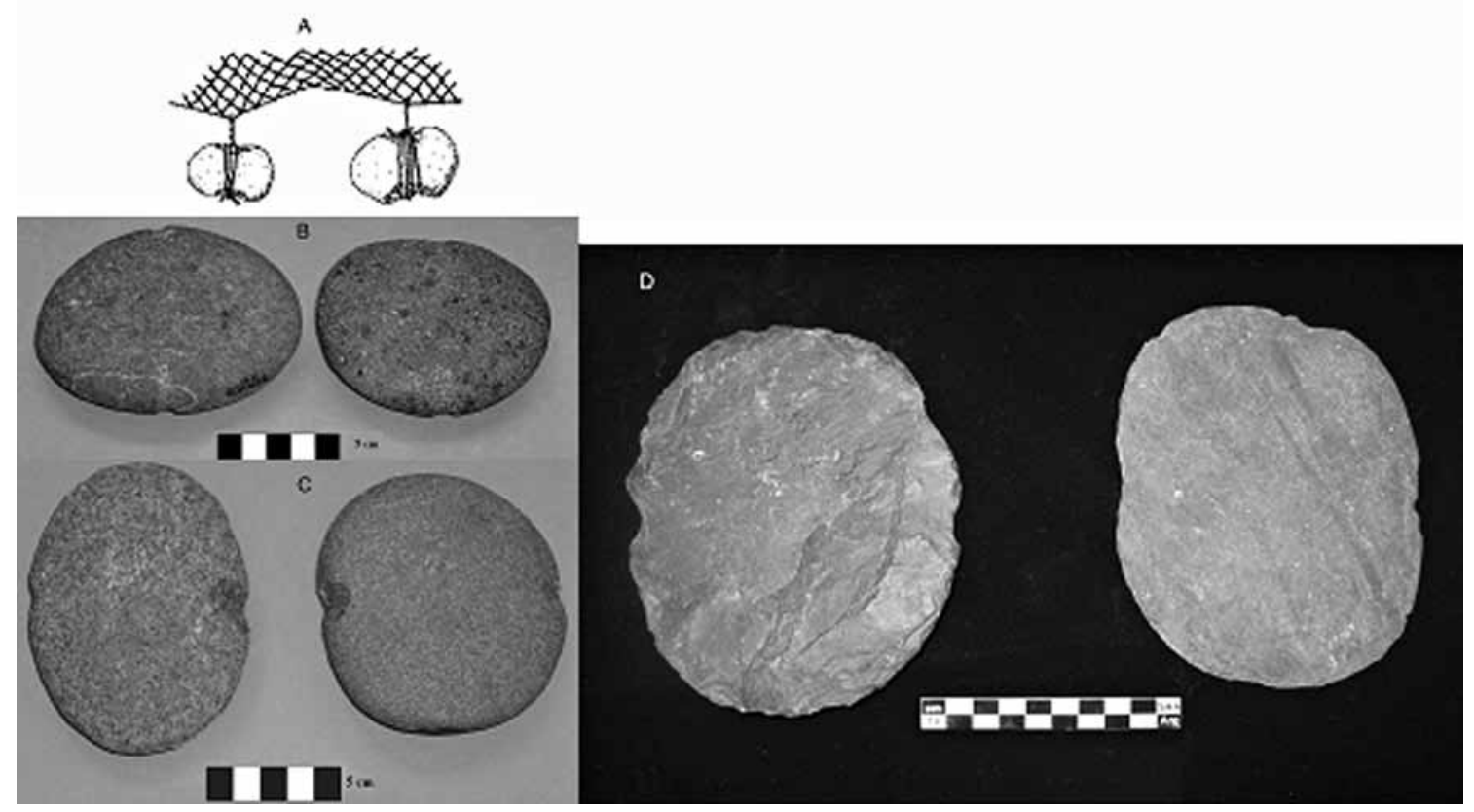

Fig. 9. A): Recreación de una red con pesas líticas (Cleyet-Merle 1990). B): Piezas con semisurco lateral, sitio PC-3. C): piezas con muescas laterales, sitio PC-3. D): piezas de recolección superficial, sitio Cabo Negro, estrecho de Magallanes.

de la punta homónima. El estudio de pesos líticos hallados en gran cantidad y concentración en el contexto, además asociado a un predominio de restos de róbalo en contraste a las aves y mamíferos, indica el rol principal de la actividad de pesca en este campamento, además de mostrar un uso especializado y reiterado de este sitio (Massone y Torres 2004). Las piezas están todas hechas sobre guijarros redondeados de sección muy aplanada y presentan muescas o semisurcos en la sección más angosta y transversal a la pieza, pesan entre $300 \mathrm{y}$ 1000 grs, y la mayor parte entre 700-800 grs. (Fig. 9 b-c) (Torres 2007b). Basándonos en la información etnográfica sobre el uso de pesos de líneas de pesca, la información arqueológica de sitios canoeros y referencias de otras áreas de estudio, sobre lastres para red; se puede desprender que las piezas de PC-3 se asemejan a lastres para redes. Este tipo de red debió abandonarse en momentos tardíos por lo que no fue registrada etnográficamente (op. cit). No obstante faltan más datos, además de los del sitio PC-3, para precisar esto como fechados absolutos, asociación de estas piezas a contextos estratigráficos y su relación a la estructura de los conjuntos ictioarqueológicos. La estimación de la talla de los róbalos puede ser un indicador del uso de redes o algún tipo de criterio o método de captura selectivo, ya que tienden a agruparse en rangos superiores a los $50 \mathrm{~cm}$ y se da una concentración en los $80 \mathrm{~cm}$. Por último en las cercanías del sitio hay pequeños cauces remanentes, que pudieron en el pasado haber formado un ambiente de orilla con condiciones diferentes a las actuales.

En Punta Baxa 7 también se hallaron piezas, aunque dispersas en una amplia área, algunas por su tamaño y forma, podrían haber sido utilizadas como de pesas de líneas de pesca, se encuentran asociadas en estratigrafía a escasos restos de peces; presentan una datación de $1.210 \pm 40$ años AP y $1.360 \pm 40$ años AP (Morello et al. 2005). En el sector de bahía Inútil, localidad de Marazzi hay concentraciones de pesos líticos similares a los de PC-3 y diferentes a las piezas de sitos arqueológicos canoeros y las descritas etnográficamente (Torres 2007b). Un problema es que al ser contextos superficiales en bermas antiguas de playa, presenta dificultades en su adscripción temporal y cultural. Marazzi-30, que presenta una concentración de estas piezas, no tiene asociación a otros elementos culturales; igualmente en Marazzi-1B y Marazzi-1/sector 4 , que pese a haber otras evidencias, los procesos de deflación del sector pudieron haber ocasionado 
palimpsesto de los eventos ocupacionales. Pese a estos problemas, el conjunto de bahía Inútil tiene características comunes; en general son concentraciones superficiales acotadas, la mayoría de los ejemplares son de granito, sección biconvexa y surco con refuerzo o sólo muescas, y en todos los casos los surcos se ubican en el eje transversal de la pieza.

En cambio en los sitios PC-3 y PB-7 hay mayor resolución de la temporalidad del contexto $y$ su adscripción cultural, ambos se vinculan a cazadores terrestres tardíos. Se destaca que en PC-3, una pieza fue encontrada en estratigrafía y asociada a un predominio de fauna ictiológica en comparación a la demás fauna vertebrada. Tanto en PC-3 como los conjuntos de bahía Inútil son concentraciones de pesos en un área delimitada, similar a algunos conjuntos de pesas de red de otras áreas (Bustos y Vergara 1998, Greenspan 1998). De acuerdo a los datos mencionados, es posible que se estén dando dos modalidades de pesa con redes, una más antigua ca. de 2.500 años AP con lastres y orientada a la pesca costera, y en tiempos históricamente más recientes el uso de redes de mano orientada principalmente a la pesca en lagos, ríos, desembocaduras y lagunas, $y$ en algunos casos en el mar. No obstante por el momento estas evidencias están registradas sólo en el sector del estrecho de Magallanes y no en la vertiente atlántica de Tierra del Fuego. Esto pudo ser resultado de una variación de la adaptación tecnológica de los grupos cazadores terrestres que frecuentaban el litoral del estrecho de Magallanes. Llama la atención el parecido entre las pesas líticas del contexto de PC-3 con artefactos de contextos de la costa de Patagonia continental, como son los artefactos discoidales con extracciones en sus extremos, a modo de muescas, hallados en el sitio HST01AM (750 \pm 70 años AP, $890 \pm 90$ años AP) en la ría del Gallegos, Punta Bustamante (Mansur 2007). Estas piezas son excepcionales en la costa atlántica y fueron interpretadas como pesas de redes para la pesca, el sitio además tiene restos de peces como Merluccius hubbsi, Acanthisticus brasiliensis, Austrolycus laticinetus y probablemente Eleginops maclovinus. Estas piezas discoidales también son muy similares a algunas halladas en el sitio Cabo Negro, al norte del estrecho de Magallanes, principalmente su morfología y tipo de modificaciones (Fig. 9-d). Bastante más al norte en el golfo San Matías, provincia de Río Negro, estudios de pesos líticos relacionados a la pesca, plantean que la variable del tamaño de las piezas se relaciona con los requerimientos de mantener la estabilidad del sistema técnico empleado en ambientes con distinta energía (Scartascini y Cardillo 2009), como sectores de corrientes, mayor oleaje o marismas de menor energía, por ejemplo. En cambio la forma y la ubicación de su modificación se podría relacionar más con diferencias morfofuncionales de distintas tecnologías de pesca, como pesos para redes o líneas de pesca (op. cit).

En general, hay una serie de expectativas sobre el uso de redes de pesca, en comparación a un método de pesca individual, que implican alta inversión de energía en la elaboración, mayor cantidad de personas necesarias para su uso en comparación a un método individual (depende de la red), un alto retorno en un evento de captura y menores dificultades en su manejo (en el caso de las redes de orilla manuales). El uso de líneas de pesca con o sin carnada y peso, implica menor inversión de energía en su fabricación, requerirían de sólo un sujeto para su utilización y también conlleva a un menor retorno en la captura. Lo que se refiere a la explotación de ambientes costeros intermareales, la pesca con redes es de preferencia en sectores despejados como playas abiertas de sustrato arenoso o de bloques y cantos; en cambio, la línea de pesca puede ser usada tanto en dichos ambientes, como también en sectores rocosos o topografías más irregulares, donde hay bosques de algas, por lo que se accede a otros ensambles de fauna ictiológica.

\section{Uso de corrales de pesca en Tierra del Fuego}

Dar una adscripción cultural a los corrales de pesca situados en bahía Inútil es problemático, ya que por el momento no se han registrado contextos arqueológicos directamente asociados a ellos. Tampoco existen estudios tipológicos que describan la variedad de corrales de piedra en el área de los archipiélagos meridionales y Tierra del Fuego, que consideren sus atributos tecnológicos, morfológicos y su dispersión espacial. Por el momento sólo se registra un dato del uso de este tipo de tecnología por los selk'nam, el que dice relación con las actividades de pesca con red [...]Las mujeres no participaban de este tipo de pesca, como tampoco en la que practicaban construyendo diques en las 
mismas desembocaduras... (Chapman 1989:151). En contraste, sí existe información más detallada del uso de corrales de piedra y confección en manos de grupos fueguinos canoeros (Lothrop 1928, Emperaire 1963, Vega 1995, Bridges 2000). Esto más allá de aclarar el origen de los corrales de bahía Inútil, permite entender el funcionamiento de dicha tecnología y las conductas implicadas en su uso. L. Bridges señala sobre los yámanas que la captura de róbalos y pejerreyes se hacía con la participación de todo el grupo; durante las altas mareas los peces ingresaban a la ensenada, cerca de donde varaban había murallas de piedra, que según el autor, [...]son construidas por los antiguos moradores del país... (2000:95-96). Estos muros quedan un metro o un poco más bajo del agua en los eventos de altamarea. Antes de capturar los peces, los indígenas ponían ramas sujetas con piedras sobre los muros para que al bajar la marea el agua escurriera entre las ramas y queden los peces atrapados (op cit). Estas paredes son interrumpidas por espacios en el centro, que también se obstruían con ramas o una red de fibra para que no pasaran los peces; aquellos que lograban pasar por las fallas de la barricada, eran capturados utilizando el arpón (op. cit). Lothrop (1928:160), también menciona el uso de corrales de pesca por parte de los yámanas, sin embargo, es imprecisa la información sobre si lo observó directamente o si se basó en las descripciones realizadas por la misión científica de Cabo de Hornos (Martial et al. 2007). Lo que sí queda claro es que se refiere al uso de hileras de palos o estacas como corrales. Por tanto, sería una variación de esta técnica utilizada por los mismos grupos. Esto a su vez es similar a algunos corrales observados actualmente en Chiloé (Álvarez et al. 2008).

En cuanto a los grupos kawésqar, C. Vega (1995:40), basándose en los relatos de Alberto Achacaz, señala que estos grupos usaban corrales de pesca antiguos que se encontraban en la orillas de la playa y utilizaban las mismas piedras disponibles en el litoral. Se confeccionaban antes que subiera el mar, unos $4 \mathrm{~m}$ más afuera de la línea de baja marea. En la parte del cierre del corral se colocaban dos palos con un cuero de lobo de mar a modo de portón, y rellenaban con piedras la parte baja para evitar que se escaparan los peces. En cuanto a las dimensiones del corral, se extendían unos $6 \mathrm{~m}$ de largo por $10 \mathrm{~m}$ de ancho, siendo morfológicamente cuadrados (op. cit). En esta observación se debe considerar el posible aporte técnico de la tradición chilota en el área, especialmente si se trata de una información relativamente reciente. Por otro lado, existen antecedentes etnográficos sobre la presencia esporádica de kawésqar en el litoral de bahía Inútil y que pudieron estar en contacto con los selk'nam (Emperaire 1963:64). Por consiguiente, existe la posibilidad que la construcción de alguno de estos corrales esté ligado a la presencia de estos grupos en el litoral de dicha bahía.

Tanto para los yámana como para los kawésqar la captura de peces era muy abundante por medio de corrales de piedra. Bridges (2000:96) señala que se capturaba una tonelada o más de pescado. En cambio Achacaz indica que se capturaban entre 60 a 70 presas (Vega 1995). Al parecer estos eventos no fueron frecuentes, puesto que el primer autor menciona que antes que se junte esta cantidad de peces en la misma ensenada, puede que pase mucho tiempo. El pescado consumido en estas instancias, con mayor frecuencia, es el róbalo y en menor medida el pejerrey, puesto que el primero se acerca frecuentemente a la playa y además que es fácil de preparar (Vega 1995:40). Emperaire (1963:182), señala que en la memoria de los kawésqar antiguos no existen recuerdos de haber utilizado en otros tiempos anzuelos, redes, ni represas. Sin embargo, menciona que en lugares de baja pendiente donde desemboca un río, se hallan restos de antiguos diques de piedra que bloquean completamente la entrada. Estos muros tienen unos $30 \mathrm{~cm}$ de alto y deben ser recubiertos completamente por la alta marea (Emperaire 1963:191). Estos diques permanentes al parecer son equivalentes a los corrales de pesca, puesto que los compara con los corrales usados en Chiloé mencionados por P. Agüero (op. cit.). Tanto para los yámana como para los kawésqar, se menciona el uso de murallas de piedra como diques (Emperaire 1963, Bridges 2000). Sin embargo, sólo para los segundos se señala el concepto de corrales propiamente (Vega 1995). Ligado a ello, Emperaire (1963:125), sugiere que los kawésqar históricos habrían reutilizado tranques donde antiguamente sus antecesores atrapaban pejerreyes y róbalos. Probablemente estos tranques eran más cerrados, y posiblemente son similares a los descritos por A. Achacaz (Vega 1995:40). Emperaire, señala que dichos tranques eran utilizados sólo por las pocas 
familias que persistían hasta ese momento en su modo de vida nómade (1963:125).

Este tipo de arte de pesca y sus variaciones, han sido estudiadas en profundidad en la isla de Chiloé y las islas adyacentes por su lado oriental (Munita et al. 2004, Álvarez et al. 2008). En la actualidad aún hay habitantes de la zona que mantienen el uso tradicional de este arte de pesca y que a esto se asocian prácticas rituales de las poblaciones chilotas. Por lo tanto la amplia dispersión de estas técnicas de explotación de peces en una extensa área costera, habitada en el extremo sur por yamanas y kaweskar, los chonos en los canales septentrionales y huilliches en la zona de Chiloé, permite plantear el uso de corrales de piedra, como una co-tradición generada por las dinámicas de contacto y movilidad de estos grupos de adaptación costera (Álvarez et al. 2008). Esta circulación de población, de conocimientos e ideas, posiblemente se ha venido desarrollando desde tiempos prehistóricos hasta la actualidad.

\section{Corrales de pesca en bahía Inútil}

Este arte de pesca es un método pasivo de alta eficacia y captura masiva. Para la decisión de su construcción en un lugar se deben considerar una serie de factores ambientales. Las características topográficas de las playas del norte de Tierra del Fuego permiten que en las mareas bajas quede expuesta una gran porción de playa generalmente sumergida. La baja angularidad de la pendiente y las playas constituidas por cantos y bloques, en las marejadas fuertes forma acumulaciones de rodados que llegan a generar pozones de considerable profundidad. Estas condiciones naturales permiten el uso de pozones sin una mayor modificación del ambiente, $y$ por otro lado, permiten el uso de estas condiciones ventajosas realizando algunas modificaciones para maximizar su eficiencia. Igualmente se requiere del conocimiento ecológico y biológico de las especies que se quieren capturar, los ambientes que frecuentan, el momento del día en que se concentran en el sector de orilla y sus recorridos migratorios. Los corrales situados al oeste y este del poblado de Cameron (bahía Inútil), son resultado del aprovechamiento de la baja pendiente, los pozones de marea y de las acumulaciones de guijarros depositadas naturalmente, reforzándolos con acumulaciones intencionales de piedras en el lado que enfrenta la marea. La obser- vación de la distribución y forma de estos corrales es posible cuando hay bajas mareas ${ }^{6}$. Las formas predominantes son las circulares, semicirculares, aunque también hay formas irregulares y alargadas.

Los corrales al suroeste de Cameron, muestran que la distancia entre la línea de alta marea y baja marea es aproximadamente de $262 \mathrm{~m}$. A los $122 \mathrm{~m}$ de la línea de baja marea aparece una poza natural grande, y a los 159 m un corral circular formado por acumulación de rodados naturales y parcialmente perfeccionado por modificaciones intencionales en el sector que enfrenta la marea. Hacía el este y a $18 \mathrm{~m}$ de la línea de alta marea, se sitúa un corral semicircular que expone la parte convexa hacia el mar. Circunscrito al interior de este corral y 9 metros más hacia la línea de alta marea, se emplaza otro corral con las mismas características de $20 \mathrm{~m}$ de ancho y 10 m de largo (Fig. 10). Continuando con la descripción, hacia el suroeste se encuentra otro corral en este caso en forma de "U" y de aproximadamente $70 \mathrm{~m}$ de largo. Comienza a la misma altura que el corral semicircular más grande, pero posee mayor longitud en dirección hacia la barranca. Una de las paredes de este corral es la misma del corral semicircular más grande. Muy próximo a estos corrales desemboca un pequeño riachuelo. Muchas de las acumulaciones intencionales de piedra se encuentran enfrentando la marea y en algunos casos aprovechan las concentraciones naturales como parte del cierre del corral. El tamaño de los clastos ocupados es variado, desde 20 a $40 \mathrm{~cm}$, en algunos casos se usan como parte del muro grandes bloques de aproximadamente $1 \times 1 \mathrm{~m}$, e incluso, hasta $2 \times 1 \mathrm{~m}$. Otro aspecto técnico considerado es un desagüe en el lado del corral que enfrenta a la línea de baja marea. Por último, los corrales por lo general presentan una altura de 30 a $40 \mathrm{~cm}$, lo cual coincide con lo planteado por J. Emperaire, el que estima una altura de $30 \mathrm{~cm}$ (1963:191). La buena conservación del apilamiento de piedras, permite que se pueda determinar la cantidad de corrales que existe en este sector, describir su forma y aspectos técnicos de su construcción y uso. El estado de preservación se puede deber a que fueron construidos recientemente o a que corrales antiguos fueron reutilizados y restaurados. Por el momento, esta situación no permite saber con claridad quienes

6 Observaciones realizadas el día 6 de diciembre del 2002, a las 8:00 PM. 


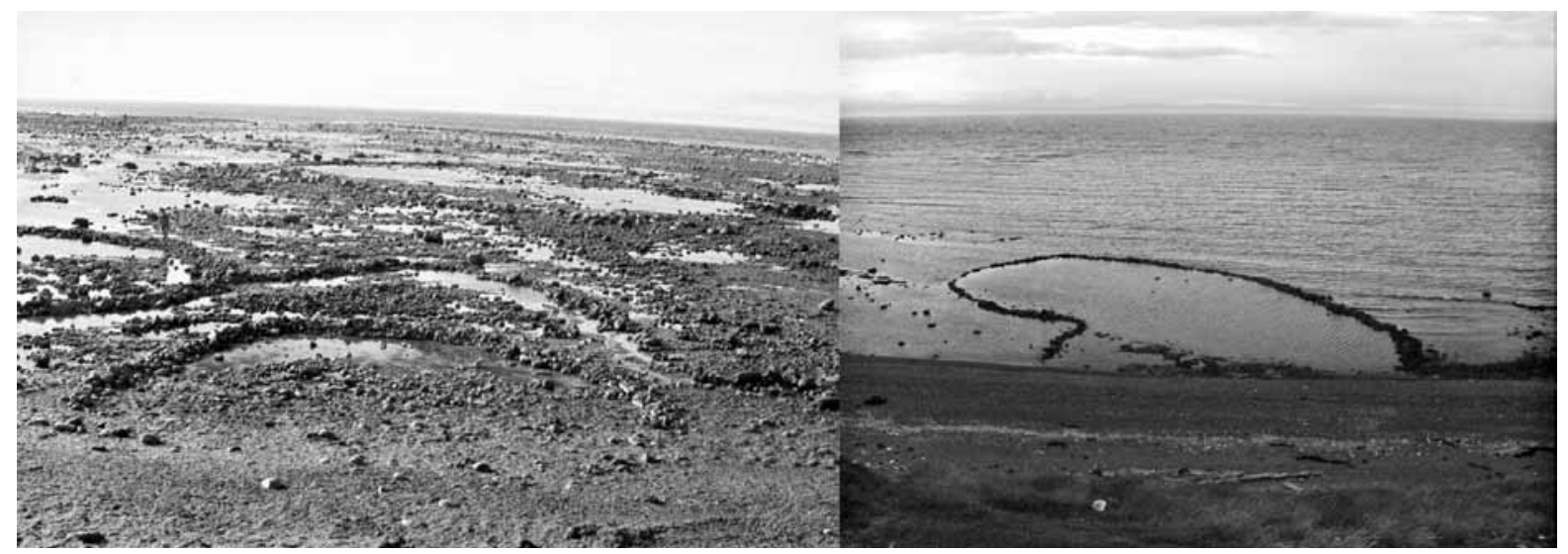

Fig. 10. Izquierda: Corrales de pesca, en forma de semicírculo al suroeste de Cameron. Derecha: corrales en marea alta al noreste de Cameron.

fueron los constructores de estos corrales de pesca. Tampoco sabemos si utilizaban otros materiales complementarios, como las varas, ramas o redes, utilizadas en los corrales de la zona de Chiloé (Álvarez et al. 2008). Si bien, la morfología de los corrales es variada, la mayoría son de forma circular o con muros curvos. Por su parte, D. Achacaz (Vega 1995: 40), menciona que la forma de los corrales usados por sus antepasados kawésqar son cuadrados, forma que no se observa entre los corrales del oeste y este de Cameron. Esta morfología se esboza en algunos corrales emplazados entre río Torcido y Marazzi, sin embargo, se encuentran muy deteriorados como para definir con claridad este patrón. Las condiciones de estos últimos sugieren que se dejaron de utilizar hace bastante tiempo, probablemente antes que los de Cameron, que se encuentran en mejor estado. Además, son los únicos corrales que, por el momento, se encuentran asociados espacialmente a un sitio arqueológico en bahía Inútil (sitio BI-18).

En cuanto a la asignación cultural de los corrales de pesca de bahía Inútil, una forma de aproximarnos a esta problemática, es la localización y posterior evaluación de sitios arqueológicos próximos a estos corrales, como es el caso del sitio BI-18; esto bajo la idea que entregaría datos sobre quienes construyeron y utilizaron esta tecnología de pesca, no obstante no necesariamente son contemporáneos. Por otro lado, esta la presencia de población de origen chilote-huilliche en la zona, los que pudieron haber adaptado esta arte de pesca tradicional usada hasta la actualidad en la isla de Chiloé y sus islas orientales. Esto parece lógico ya que además las condiciones ambientales de este sector de bahía Inútil permite la construcción de sistemas de corrales similares a los de la costa de Chiloé, no obstante, estos últimos se construyen preferentemente en los embahiamientos de la parte final de una península (Álvarez et al. 2008). En definitiva, los movimientos de poblaciones a lo largo de los archipiélagos patagónicos ha generado un consecutivo flujo de información, intercambio de ideas, conocimientos y tradiciones, por lo que el registro arqueológico debe ser reinterpretado permanentemente considerando este proceso dinámico.

\section{Gustos y restricciones en el consumo}

Muchas de las actividades desarrolladas en los campamentos litorales no necesariamente tienen relación con lógica o principios económicos, por lo que, por ejemplo, sólo basarse en conductas de forrajeo optimo (Bettinger 1991), puede enmascarar explicaciones desde otros aspectos culturales. De esta manera los componentes ideacionales en las estrategias de subsistencia, en algunos casos son determinantes en la toma de decisiones y en los patrones de explotación. Tal es el caso de algunos tabúes en torno a comidas o animales que pueden incidir en las restricciones de consumo de ciertos taxa, los que muchas veces desde el punto de vista de una economía óptima, son recursos de alta productividad. De tal modo la información que da la etnografía puede servir como medio para calibrar las interpretaciones de los conjuntos zooarqueológicos. Desde una perspectiva más bien económica, muchas 
de estas variaciones en los patrones culturales de consumo no resisten un mayor análisis (Politis y Saunders 2002, DeBoer 1987).

En el caso de las restricciones de consumo de peces, se ha señalado que los selk nam se abstenían de algunas comidas especialmente de algunas aves y peces ya que creían que consumían cadáveres humanos (Coiazzi 1997:59). No queda claro que tipos de peces eran los que no eran consumidos. En el caso de los grupos yámana existía el tabú del consumo del róbalo (Eleginops maclovinus), este factor fue considerado en el estudio ictioarqueológico de sitios canoeros tardíos, comparando el registro arqueológico con los costos y beneficios de la explotación de esta especie (abundancia, frecuencia de encuentro, valor nutricional, costos de captura, etc.), sus aspectos ecológicos, tafonómicos y sus implicancias tecnológicas (Fiore y Zangrando 2006). Se observó que pese a esperar una alta explotación del recurso por su buen rendimiento; su escasez o ausencia es casi absoluta en comparación a otros recursos ictiológicos de menor rendimiento e incluso con más bajas posibilidades de conservación. De esta manera la información etnográfica permite explicar esta ausencia por el rol de este taxón en algunas actividades ceremoniales (op. cit.). Por el contrario, según la información etnográfica los cazadores terrestres de Tierra del Fuego consumían principalmente esta especie, ya que es la que predomina en los sitios arqueológicos estudiados al norte de Tierra del Fuego, además en la actualidad es la especie más abundante y disponible a lo largo de todo el año en la mayoría de las bahías y desembocaduras del estrecho de Magallanes (Massone y Torres 2004, Torres 2006, Torres 2007a). Una observación muy singular hecha por Gallardo sobre los selk nam, dice: [...]Puede asegurarse que los onas son lujuriosos hasta el exceso, no siendo una de las menores causas para ello el uso del pescado, lo que en ciertas ocasiones y por largo tiempo los hace exclusivamente ictiófagos... (1998:143). Esta es una observación que no es para nada recurrente entre los relatos etnográficos, pero da indicios del consumo de este recurso no necesariamente ligado a un costo o un beneficio económico. Estos datos permiten generar herramientas interpretativas para abordar contextos arqueológicos, por el momento, inusuales y que pudieron tener un origen en parte extra-económico.

\section{DISCUSIÓN}

Las observaciones etnográficas sobre la importancia de la pesca y los modos de explotación de los grupos indígenas que poblaron Tierra del Fuego desde la prehistoria hasta tiempos históricos, no sólo da cuenta de su exitosa adaptación al medio costero, el grado de planificación y especialización, sino también permite entender procesos continuos de intercambio de información y de tradiciones tecnológicas entre los cazadores terrestres de Tierra del Fuego y Patagonia, como también entre los primeros y los grupos de adaptación marítima tanto del extremo austral (yámanas, kawesqar y sus antecesores), como los grupos de los canales septentrionales. Esta especialmente contrastado en momentos históricos hasta la actualidad por la migración chilota-huilliche.

En el caso de los grupos cazadores-recolectores-pescadores marinos, ante la importancia que tenia este recurso en su estrategia de subsistencia, es esperable el desarrollo de una tecnología eficaz y de mayor especialización en la explotación de este tipo de recursos. Pese a esto la única tecnología de pesca masiva comparable en términos de retorno, son los corrales de pesca, no obstante, por el momento no se puede definir desde cuando se comenzó a utilizar esta tecnología. No se descarta que su incorporación como estrategia de pesca haya sido en tiempos bastante más tardíos que el de las primeras ocupaciones canoeras en los canales patagónicos meridionales, y que posiblemente tenga relación con la dinámica de movilidad de grupos canoeros (chonos o antecesores) o huilliches de la zona de Chiloé.

Los cazadores terrestres de Tierra del Fuego, en tanto, contaban con estrategias de explotación de recursos intermareales, en gran medida influida por las características topográficas, como la baja pendiente que permite la formación de intermareales muy extensos y con pozones de marea. De esta manera, se logra un buen acceso a los sectores de concentración de fauna bentónica litoral, y también a sectores cercanos al submareal en las bajas mareas. Bajo estas condiciones la disponibilidad y eficacia en la captura no requiere necesariamente especialización tecnológica para la pesca en aguas someras. No obstante, si se necesitaba de una estrategia planificada, ya que el conocimiento sobre 
qué momentos del día o en qué períodos del año se produce una explotación más ventajosa, indica una estrategia dirigida y no oportunista, como muchas veces se piensa cuando se carece de una estrategia tecnológica de por medio. Por otro lado está el complemento de tecnologías de captura que ofrecen un mayor retorno, como son las redes, que además de aumentar el grado de planificación y especialización, refuerza el éxito de la pesca. Otro indicio más de planificación es el descrito para cazadores terrestres históricos, que tanto hombres, como mujeres, niños y ancianos participaban y aportaban en el desarrollo de la actividad especialmente en la pesca en ríos y desembocaduras. Esta modalidad, como también es el caso de los corrales de pesca, indican algún grado de planificación y organización social. Ligado a esto, el uso de corrales de pesca en Chiloé insular, incluye una serie de concepciones mágicas que formaban parte de la lógica con que los habitantes del lugar concebían la realidad. Su ubicación, propiedad y uso reflejaban las diferencias sociales establecidas entre las familias, recreando en el intermareal la distribución jerárquica de la comunidad (Álvarez y Bahamonde 2003).

El uso de redes en el norte de Tierra del Fuego, y puntas óseas en la costa atlántica, permite ver la variabilidad de tácticas empleadas y las diferencias adaptativas de grupos que son parte de una unidad cultural. Esto puede tener que ver con la presencia de grupos que en un momento determinado tuvo mayor dinámica de contacto con poblaciones que tenían estos conocimientos tecno-económicos. Mientras tanto otras quizás no tenían un buen acceso a esta situación, por encontrarse más aisladas geográficamente o culturalmente, por lo que desarrollaron otras tácticas. Una estrategia oportunista, es el aprovechamiento de peces varados en el intermareal circunstancialmente, no obstante hay relatos que hablan del desprecio de los selk nam del sur por comer animales asociados a cadáveres, tales como ciertos peces y aves (Coiazzi 1997). No obstante, hay otros relatos que si mencionan el aprovechamiento de peces varados, relacionado con los hábitos de los selknam del norte (Gallardo 1998).

En general, las evidencias indican que en los distintos períodos evaluados, la pesca se realizó preferentemente en la estación estival, tanto en las ocupaciones más tardías como en las más antiguas. De todos modos es preciso continuar estudiando esta materia para lo cual es necesario testear otras técnicas de estimación de estación de captura, ya que siempre los indicadores de periodos cálidos toman más fuerza que los de estaciones más frías, por tanto, debilita su detección. De todos modos la productividad de los ambientes costeros es claramente mayor en los meses de primavera y de verano, lo cual puede extrapolarse al pasado, no obstante, si consideramos que en el norte de Tierra del Fuego la presencia de un recurso clave como es el guanaco está a lo largo de todo el año en la costa aunque variando su composición energética, da más posibilidades del uso del espacio litoral. En cambio en la costa sur de Tierra del Fuego, en invierno hay restricciones ambientales en la disponibilidad de este recurso (Stuart 1977). Además en el norte, también hay ciertos recursos bentónicos que entregan un buen rendimiento económico y que se mantienen a lo largo de todo el ciclo anual, como es el caso de la pesca del róbalo en la costa del estrecho de Magallanes.

Por otro lado, se puede establecer que los grupos cazadores terrestres que ocuparon el litoral de Tierra del Fuego hacia los 5000 años AP, ya incluían dentro de estrategia de subsistencia la actividad de pesca, sin embargo no se tiene claro si era un patrón generalizado, ya que Marazzi 1 es el único sitio hasta la fecha que cuenta con evidencias de este tipo. Posteriormente desde los 2300 años AP hasta el período de contacto, posiblemente utilizaron estrategias planificadas para la explotación de peces litorales. No obstante fue variando el modo de uso de una estrategia tecnológica como pudo ser la red de pesca. El uso de redes implicaría una estrategia tecnológica de alta curaduría, dada la alta inversión en materiales, en trabajo de elaboración y en su mantención. El sitio Punta Catalina 3, es el contexto que representa mejor el rol de la actividad de pesca especializada en un campamento de cazadores terrestres en el norte de Tierra del Fuego. Esta fue la actividad de apropiación prioritaria en el campamento, evidenciada por tecnología y restos zooarqueológicos. La reutilización del emplazamiento observada por la cantidad de pesas líticas de redes y su reutilización para otras funciones, además de la organización espacial de las áreas de actividad; permite desprender la planificación de las ocupaciones pautadas de este campamento. Este planteamiento se refuerza con la baja recurrencia 
de estos conjuntos de pesas líticas en general en la costa norte de Tierra del Fuego, no obstante, cuando se registran se encuentran en sectores acotados y concentrados. Otra conducta que se puede inferir es el abandono temporal de las pesas para su uso posterior, posiblemente porque en los campamentos del interior no serían necesarios, además del peso que implicaría su transporte. Ligado a esto, se sugiere que existirían ciertos puntos de la costa donde se accedía pautadamente para explotar intensivamente los recursos ictiofaunísticos, de forma planificada y en la mayoría de casos asociada a otras actividades de apropiación igual de importante en la ocupación, como en Marazzi 32 y Marazzi 38. Por el momento este patrón se observa de manera clara en los sitios más tardíos, es decir en los últimos 1000 años AP.

Las pesas líticas interpretadas como pesas de redes en el caso de los sitios Marazzi 30 y Punta Catalina 3, presentan fechas más tempranas o previas por lo menos en mil años al período de contacto europeo (Massone y Torres, 2004, Morello et al. 2005). Esto sugiere como hipótesis que estos lastres no fueron empleados en momentos tardíos y que, por tanto, se entiende la ausencia de descripciones en momentos históricos. Ello no significa el abandono del uso de redes, puesto que se reporta su uso por parte los selk nam y haush históricos. Esto también se condice con la presencia de desechos, preformas y piezas terminadas de boleadora, que pueden indicar usos tecnológicos anteriores, ya que se encuentran abundantes en la estepa norte; no obstante nunca se observó a algún indígena utilizarlas (Gusinde 1982). De tal manera, la profundidad cronológica de PC-3, sumado a la presencia de pesas para la pesca y su asociación a artefactos en desuso en momentos de contacto europeo en Tierra del Fuego, como es el uso de bolas líticas, indican cambios en el tiempo en las estrategias de subsistencia de estos cazadores terrestres.

Sobre la variabilidad espacial de los conjuntos ictioarqueológicos, los sitios de la vertiente atlántica muestran una biodiversidad bastante diferente a la de los sitios del estrecho de Magallanes, esto posiblemente se relaciona con las condiciones ambientales $y$ disponibilidad de este recurso en la costa de la vertiente atlántica. No obstante también puede deberse a parámetros culturales que definieron patrones de explotación y consumo. Ligado a esto, se observan similitudes en el uso de ciertas tecnologías como el uso de redes con lastres en la costa continental y sur del estrecho de Magallanes y en la costa atlántica continental. En cambio, es diferente la distribución de puntas óseas hechas sobre hueso de mamífero terrestre, por el momento no hay evidencias en la costa sur del estrecho de Magallanes, más bien se registra en sitios de la vertiente atlántica, en Tierra del Fuego y en la costa continental del estrecho. Queda por explorar las causas de estas similitudes y diferencias en las tradiciones tecnológicas en un plano tanto temporal y espacial, también queda por entender cual es su relación con las poblaciones que ocuparon el norte y sur de Tierra del Fuego y si estas diferencias responden a cambios en las adaptaciones de los mismos grupos culturales a través del tiempo, o a la presencia o contacto de grupos distintos.

En los campamentos costeros de cazadores recolectores terrestres se producen problemas al sobredimensionar o subestimar un tipo de estrategia de subsistencia, y el rol e intensidad de estas actividades a partir de los conjuntos arqueofaunísticos. Un ejemplo de esto se da con la recolección de moluscos, por el tamaño de los depósitos, preservación, la alta visibilidad y su recurrencia en los ambientes litorales. Esto va en desmedro de los sitios más pequeños, con mal estado de conservación y/o menos visibles; o dirigidos a otras actividades con evidencias menos visibles. Sumado a este punto, están los agentes tafonómicos naturales y culturales, que también inciden en la sobrerepresentación o en la subvaloración de un recurso. Ni la presencia ni la ausencia de artefactos asociados a la pesca en el registro arqueológico, permite a cabalidad ver la importancia o la intensidad del consumo de estos recursos en la dieta de cazadores terrestres. Como se señaló en las descripciones etnográficas, la pesca sin el uso de una tecnología correspondería a una estrategia muy utilizada, por lo que disminuye las posibilidades de registrar su importancia en contextos arqueológicos. También se puede dar una discordancia entre la presencia de un tipo de tecnología de pesca y un tipo de campamento. Estudios etnoarqueológicos en otras áreas han permitido esclarecer conductas que producen incoherencias entre las actividades realizadas en un campamento y los artefactos hallados en éste. Se ha señalado que desde los campamentos de pesca estivales se trasladan tecnología especializada de pesca a los campamentos base invernales donde se guarda hasta finales de primavera donde 
comienza el periodo de pesca (Whitridge 2001: 3536). Esta conducta genera una sobrerepresentación de artefactos de pesca en campamentos donde no fueron utilizados y una subrepresentación de restos ictiofaunísticos (op. cit.). En el presente estudio es esperable la presencia de pesas de red en las cercanías o en el mismo campamento donde se ocupó, especialmente si se considera la cantidad de piezas y peso que implicaría su transporte. Además se trata de artefactos expeditivos y especializados que pudieron ser usados exclusivamente en los campamentos litorales.

Por otro lado, la evaluación de conjuntos zooarqueológicos en sitios ubicados en ambientes interiores, no entregó resultados positivos sobre la presencia de restos de peces, sólo algunas evidencias malacológicas por lo que puede atribuirse al circuito de movilidad a espacios costeros. De esta manera, hasta el momento no hay registro de evidencias concretas del transporte de peces a campamentos interiores (sitios de Cerro los Onas) y tampoco a campamentos cercanos a la costa, pero no inmediatos al litoral (Myren 1 y Marazzi 14). Esta ausencia, tampoco permite, por el momento, hablar de pesca en ambientes fluviales, no obstante, en las fuentes etnográficas se señala la pesca tanto en lagos como ríos. A estos se agrega que en las ocupaciones arqueológicas litorales, las estrategias de pesca oportunista y planificada se realizaron próximas a los campamentos, y las actividades de faenamiento, preparación, consumo y descarte, fueron hechas en los mismos asentamientos, sin mayor indicio de su traslado o almacenaje para el consumo en campamentos al interior de la isla.

Por último, quedan en evidencia las limitaciones al generalizar o extender la uniformidad de los conjuntos en un plano temporal amplio, lo que en algunos casos dificulta detectar las discontinuidades culturales representadas en el registro arqueológico y que dan cuenta de los cambios ocurridos anteriormente al período de contacto europeo. En este sentido, la búsqueda de contextos que den cuenta de variaciones es de vital importancia para tener una visión espacial y temporal más completa. Además al potenciar evidencias arqueológicas no estudiadas suficientemente, como la ictiofauna y la tecnología destinada a la pesca, se puede dar cuenta de un ámbito específico de los modos de vida de los grupos cazadores recolectores terrestres etnográficos y prehistóricos de Tierra del Fuego y nos acerca a las variaciones de las conductas adoptadas en el subsistema de asentamiento litoral.

\section{CONCLUSIONES}

Si bien es necesario desarrollar más estudios que permitan contrastar la importancia de este recurso a lo largo del Holoceno de todas formas se pueden trazar algunas ideas a partir de la información expuesta. De esta manera los resultados permiten distinguir la explotación de estos recursos desde el Holoceno medio en adelante, con variaciones de su importancia en la subsistencia y diferencias en los modos de apropiación, reflejada en cambios tecnológicos y en la configuración de los conjuntos ictioarqueológicos. Alrededor de los 2000 años AP se distinguen artes de pesca de captura masiva, como es el uso de redes con lastre, orientadas a la pesca costera y probablemente de mayor retorno a la red utilizada en momentos etnográficos. En este último periodo se observan diferencias en las estrategias de pesca entre campamentos ubicados en la costa del estrecho de Magallanes y los contextos de la vertiente atlántica, teniendo los primeros algunos rasgos similares a contextos de Patagonia continental. Hipotéticamente, el uso de lastres para redes de pesca denota un mayor contacto e intercambio de información tecno-económica entre grupos cazadores terrestres continentales y lo habitantes del estrecho de Magallanes hacia el segundo milenio AP. Lo mismo se podría plantear en momentos tardíos (aprox. 1000 años AP. momentos históricos), entre los grupos continentales y los que ocuparon la vertiente atlántica de Tierra del fuego. También se plantea que en los últimos 1000 años hay un incremento en la diversificación y consumo de peces. Por último, en momentos históricos tenemos la incorporación de tecnologías provenientes probablemente de grupos procedentes del área de Chiloé, representada por la construcción de corrales de pesca, siendo una solución óptima ante las condiciones ambientales costera de algunas zonas del estrecho de Magallanes.

\section{AGRADECIMIENTOS}

Al proyecto FONDECYT 1020004 donde se realizó gran parte de este trabajo (practica profesional y tesis de pregrado) y al FONDECYT № 
1060020 donde se profundizaron algunos puntos. A Luis Borrero y Karen Borrazzo por su valiosa colaboración en antecedentes arqueológicos y material fotográfico. A Francisco Zangrando por sus aportes en el mejoramiento del manuscrito. También a don Salvatore Cirillo, director del Museo Salesiano Majorino Borgatello, e Iván Rogel, conservador de las colecciones de dicha entidad, por permitir fotografiar la red de pesca que es parte de la exposición permanente del museo. A Gabriel Bahamonde por colaboración en la fotografía de dicha pieza. Por último, a Pedro Cárdenas por su buena memoria.

\section{BIBLIOGRAFÍA}

ALVAREZ, R. Y N. BAHAMONDE. 2003. Los corrales de pesca de San Juan de Coquihuil. Revista Suelo Americano, pp.96-103, Universidad Arcis, №5.

ALVAREZ, R., D. MUNITA, J. FREDES Y R. MERA. 2008. Corrales de pesca en Chiloé. Gobierno de Chile Consejo Nacional de la cultura y las Artes.

ARCOS D. 2002. Determinación de la capacidad de carga de las zonas estuarinas de los ríos Valdivia y Bueno, X Región (Río Bueno). En: Proyecto FIP N²000-29. Informe Final.

BELLIER, C., A. BILLAMBOZ, P. CATTELAIN, M. JULIEN, L. MONS, D. RAMSEYER, A.C. WELTÉ. 1995. Cahier VII. Élements Barbelés. Fiches typologiques de l' industrie osseuse préhistorique.Cahier VII, éléments barbelés et apparentés. Editions du CEDARC, Treignes.

BETTINGER, R. L. 1991. Hunter-gatherers: Archaeological and Evolutionary Theory. Plenum Press, Nueva York.

BORELLA, F. 2000. El aprovechamiento de cetáceos en los sitios arqueológicos de Bahía Policarpo, extremo sudoriental de Tierra del Fuego. En: Desde el País de los Gigantes: perspectiva arqueológica en Patagonia, Tomo II. Pp: 471-479. Universidad Nacional de la Patagonia Austral. Río Gallegos.

BORRERO L. A. 1985. La economía prehistórica de los habitantes del norte de la isla grande de Tierra del Fuego. Tesis para optar al grado de doctor en filosofía y letras. Universidad de Buenos Aires.

-1991. Los Selk'nam (Onas). Su evolución. Buenos Aires. Editorial Búsqueda- Yuchán.

BRIDGES, L. 2000. El último confín de la tierra. Editorial EMECÉ. Buenos Aires.

BUSTOS, V. y N. VERGARA. 1998. El Visal y Talcahuano 1, ejemplos de sedentarismo y especialización en el arcaico tardío del litoral de la VIII Región. Concepción, Universidad
San Sebastián, Serie Antropología Actas 1er Seminario de Arqueología, zona centro-sur de Chile, 1: 65-74.

CAMPAN, P. 1992. Los restos de peces de Punta María II. Palimpsesto. 2:99-106.

CAMPAN P. Y L. M. MANZI. 2000. Rayas y Centollas. Uso de la costa en Isla Grande de Tierra del Fuego a través del registro arqueológico de la fauna ictícola y las fuentes etnohistóricas. En: Desde el País de los Gigantes: perspectiva arqueológica en Patagonia, Tomo II. Pp: 533-540. Universidad Nacional de la Patagonia Austral. Río Gallegos.

CAMPAN P. Y G. PIACENTINO. 2004. Análisis Arqueofaunístico de peces del norte de la isla grande de Tierra del Fuego. 87-105. En: Temas de Arqueología. Arqueología del Norte de la Isla Grande de Tierra del Fuego.55-86. Compilado por: Luis Alberto Borrero y Ramiro Barberena.

CASTEEL R. Y D. GRAYSON. 1977. Terminological problems in quantitative faunal analysis. World Archaeology. Architecture and archaeology 9[2]: 235-242.

CHAPMAN, A. 1982. Los selk'nam, la vida de los onas. Emecé editores, Buenos Aires.

-1989. El fin de un mundo. Los Selk'nam de Tierra del Fuego. Vásquez Manzini Editores.Buenos Aires.

CLEYET-MERLE, J. J. 1990. La Préhistoire de la peche, Collection des Hesperides, Errance, Paris.

COIAZZI, A. 1997 (1914). Los indios del archipiélago fueguino. Editorial Ateli, Punta Arenas.

COLLEY S. 1990. The analysis and interpretation of archaeological fish remains. En: Advances in Archaeological Method and Theory, Vol.2, M. B Schiffer (ed), pp.207253 Academic Press, San Diego.

CORFO IFOP. 1982. Bases de un desarrollo, complemento Róbalo. Preparado por R. Busto y M. Aguayo. Corporación de Fomento de la Producción- Instituto de Fomento Pesquero, Chile.

DE BOER, W. 1987. You are what you don't eat: yet another look at food taboos in Amazonia. In R. Auger, M. Glass, S. MacEachern and P. H. Mac Cartney (eds.) Ethnicity and Culture, pp.45-54. The University of Calgary.

EMPERAIRE, J. 1963. Los nómadas del mar. Ediciones de la Universidad de Chile. Santiago.

FIORE D. Y A. F. ZANGRANDO. 2006. Painted fish, eaten fish: artistic and archaeofaunal representations in Tierra del Fuego, Southern South America. Journal of anthropological archaeology. En Prensa.

GALlARDO, C. 1998(1910). Tierra del Fuego. Los onas. Cabaut y Cia., Buenos Aires.

GOMEZ- OTERO, J., L. LANATA, A. PRIETO. 1998. Arqueología de la Costa Patagónica. Revista de Arqueologia Americana. 15:107-185. 
GRAYSON, D.K. 1984. Quantitative zooarchaeology: topics in the analysis of archaeological faunas. Orlando, Florida: Academic Press.

GREENSPAN, R. L. 1998. Gear selectivity models, mortality profiles and the interpretation of archaeological fish remains: A case study from the Harney basin, Oregon. Journal of Archaeological Science 25:973-984.

GUSINDE, M. 1982. Los indios de Tierra del Fuego. Los Selk'nam. Centro Argentino de Etnología Americana, Buenos Aires.

GUZMÁN, L. y G. I. CAMPODÓNICO. 1973. Algunos aspectos de la biología de Eleginops maclovinus (Cuv. y Val.) 1830, con especial referencia a su morfometría, caracteres merísticos y alimentación. Anales del Instituto de la Patagonia 4: 343-371.

HORWITZ, V. 2004. Arqueología de la costa atlántica septentrional de Tierra del Fuego, Argentina. En: Temas de Arqueología. Arqueología del Norte de la Isla Grande de Tierra del Fuego. 29-54. Compilado por: Luis Alberto Borrero y Ramiro Barberena.

KONIG, R. A. 1996. Contribución al Conocimiento de la Composición Física y química del "róbalo" Eleginops maclovinus (Valenciennes, 1830). Tesis de grado presentada como requisito para optar al grado de licenciado en medicina veterinaria. Universidad Austral de Chile, Facultad de ciencias veterinarias, Instituto de ciencia y tecnología de carnes. 55pag.

LAMING-EMPERAIRE, A. 1968. Le site Marassi en Terre de Feu. Rehue. Concepción. 1:133-143.

-1972. Sites préhistoriques de Patagonie chilienne. Objets et Mondes, París.

LANATA, J. L. 1993. Estados alterados: procesos de formación y conjuntos faunísticos en rancho Donata, Tierra del Fuego. Explotación de recursos faunísticos en sistemas adaptativos americanos, compilado por J. L. Lanata, pp. 163-182. Arqueología Contemporánea 4, Edición Especial. -1996. The "haush" puzzle: piecing together subsistence and settlement at the fueguian southeast. Revista do Museu de Arqueologia e Etnologia, Sao Paulo. 6:11-32.

LEGOUPIL, D. 1989. Ethno-Archéologie dans les Archipels de Patagonie: les Nomades Marins de Punta Baja. Editions Recherche sur les Civilisations. "Mémoire" no 84. -1997 Bahia Colorada (île d'Englefield). Les premiers chasseurs de mammifères marins de Patagonie australe. Mémoires de l'A.D.P.F., Recherches sur les Civilisations, Paris.

LISTA, R. 1998 (1887). Viaje al país de los onas, Tierra del Fuego. Alberto Núñez [reed]. en Obras. Buenos Aires. Confluencia, vol. 2: 9-118.
LOPEZ, H.L., M.L. GARCIA, N. SAN ROMAN. 1996. Lista Comentada de la Ictiofauna del Canal de Beagle, Tierra del Fuego, Argentina. Centro austral de investigaciones científicas, contribución científica publicación especial 85. pp. Ushuaia.

LOTHROP, S. 1928. The Indians of Tierra del Fuego. Contributions of the Museum of the American Indian, Heye Foundation, 244 pp. New York.

LLORIS, D Y J. RUCABADO. 1991. Ictiofauna del Canal de Beagle (Tierra del Fuego). Aspectos ecológicos y análisis biogeográfico. Publicaciones Especiales del Instituto Español de Oceanografía. Madrid.

MANSUR, E. 2007. Confección y uso de artefactos discoides en contextos de cazadores recolectores de Patagonia Meridional: Pesas para redes en el sitio HST01AM (Prov. Santa Cruz, Argentina). Arqueología de FuegoPatragonia. Levantando piedras, desenterrando huesos...y develando arcanos. Pp: 701-708. Editado por: F. Morello, M. Martinic, A. Prieto, G. Bahamondes. Ediciones CEQUA, Punta Arenas.

MARTIAL, L. F., J. DENIKER Y P. HYADES. 2007. Etnografía De Los Indios Yaghan. En La Misión Científica Del Cabo De Hornos 1882-1883. Por. Editores científicos D. Legoupil y A. Prieto. Ediciones Universidad de Magallanes-Instituto Francés de Estudios Andinos. 332 págs. Punta Arenas.

MASSONE, M. 1997. Prospección Arqueológica del sector comprendido entre río Marazzi y Torcido, Zona Norte de Tierra del Fuego. Anales del Instituto de la Patagonia. Serie Ciencias Sociales 25:123-136. Punta Arenas.

MASSONE, M., D. JACKSON Y A. PRIETO. 1993. Perspectiva arqueológica de los selk'nam. Colección de Antropología I. Dirección de Bibliotecas, Archivos y Museos, Santiago.

MASSONE, M. Y M. MORELLO. 2005. Los cetáceos en el mundo selk'nam estudios arqueológicos. Informe final, proyecto FONDECYT 1020004.

MASSONE, M., F. MORELLO, A. PRIETO, M. SAN ROMÁN, F. MARTÍN Y P. CÁRDENAS. 2003. Sitios arqueológicos, restos de cetáceos y territorios locales selk'nam en Bahía Inútil, Tierra del Fuego. Magallania, 31: 45-59, Punta Arenas.

MASSONE, M. Y J. TORRES. 2004. Pesas, peces y restos de cetáceos en el campamento de Punta Catalina 3 (2.300 años AP.). Magallania, 32:143-161, Punta Arenas.

MAYORGA, P. 1972. Costumbres y extinción de los indios del extremo austral. Arancibia Hnos. Santiago, Chile.

MELÉNDEZ, R., F. FALABELLA Y M. L. VARGAS. 1992. MS. Osteometría e identificación de restos ictio-arqueológicos en Chile Central. Resultados del proyecto FONDECYT 
$N^{\circ}$ 0089-91. Manuscrito conservado en la biblioteca de CONICYT, Santiago.

MORELLO, F. 1999. Cazadores terrestres del Holoceno Medio y Temprano en Tierra del Fuego : Marazzi 1, una discusión abierta. Tesis para optar al grado profesional de arqueólogo. Universidad de Chile. Santiago, Chile.

MORELLO, F., L. CONTRERAS y M. SAN ROMÁN. 1999. La localidad de Marazzi y el sitio arqueológico Marazzi I, Una re-evaluación. Anales del Instituto de la Patagonia. Serie Ciencias Sociales 27:187-197. Punta Arenas.

MORELLO, F.; L, CONTRERAS, M. SAN RÓMAN, I. MARITNEZ, F. MARTIN Y M. BAHAMONDES. 2005. El sitio Punta Baxa 7, Primera Angostura Tierra del Fuego. Informe Final, proyecto FONDECYT 1020004.

MORELLO, F. Y M. SAN ROMÁN. 2000 MS. Registro arqueológico de sitios de Primera Angostura, Tierra del Fuego. Informe Proyecto FONDART № 51237.

MORELLO, F. M. SAN ROMÁN Y A. PRIETO 2004. Informe de actividades de sondeo en el sitio Marazzi 2 sector 1 (río Torcido), Tierra del Fuego. Magallania 32:233-238. Punta Arenas.

MORENO, E., B. VIDELA., H. PÉREZ RUIZ, L. S. ASENCIO, V. LEONFORT. 2007. Busqueda de indicadores de diversificación económica prehistórica en la cuenca del lago Munster (Chubut- Argentina), primeros resultados. Arqueología de Fuego-Patragonia. Levantando piedras, desenterrando huesos...y develando arcanos. Pp:2332. Editado por: F. Morello, M. Martinic, A. Prieto, G. Bahamondes. Ediciones CEQUA, Punta Arenas.

MORENO, C. Y H. JARA. 1984. Ecological -studies on fish fauna associated with Macrocystis pyrifera belts in the south of Fuegian Islands. Chile. Mar. Ecol. Prog. Ser., 15: 99-107.

MUNITA, D., R. ÁLVAREZ Y C. OCAMPO. 2004. Corrales de piedra, pesca pasiva en la costa interior de Chiloé. Boletín de la Sociedad Chilena de Arqueología 37:6174. Santiago.

ORQUERA, L. Y E. PIANA. 1999. La vida material y social de los yámana. Buenos Aires: EUDEBA.

POLITIS, G. Y N. SAUNDERS. 2002. Archaeological correlates of ideological activity: food taboos and the spirit-animals in an Amazonian hunter-gatherer society. En: Preston Miracle (ed.) Consuming Passions. Archaeological studies of material culture. Mc Donald Institute. Cambridge University, Gran Bretaña.

PRIETO, A. 2004. MS. Redes para peces y trampas para aves: El caso selk'nam de la Tierra del Fuego. Informe de avance segundo año, proyecto FONDECYT 1020004.
PRIETO, A. y R. CÁRDENAS. 2002. Las Colecciones etnográficas fuego/patagónicas en los museos europeos. Anales del Instituto de la Patagonia. Serie ciencias humanas 30: 65-77, Punta Arenas.

PRIETO, A. Y F. MARTIN. 2005. MS. El consumo de guanaco en sitios de la costa norte de Tierra del Fuego. Informe final, proyecto FONDECYT 1020004.

QUIJADA, P. y C. CACERES. 2000. Patrones de abundancia, composición trófica y distribución espacial del ensamble de peces intermareales de la zona centro-sur de Chile. Revista Chilena de Historia Natural 73(4). Santiago.

RIOS, C. Y D. GERDES. 1997. Ensamble bentónico epifaunístico de un campo intermareal de bloques y cantos en bahía Laredo, Estrecho de Magallanes. Anales del instituto de la Patagonia, serie ciencias Naturales 25:47-55. Punta Arenas.

RIOS, C. Y L. GUZMAN. 1982. Reevaluación de la estructura de la comunidad en una playa de bloques y cantos de alta latitud (Archipiélago del Cabo de Hornos). Anales del instituto de la Patagonia Vol.13:211-224. Punta Arenas.

RIOS, C., E. MUTSCHKE Y Y. CARICEO. 2003. Estructura de población de Pseudechinus magellanicus (Philippi 1857) (Echinoidea: Temnopleuridae) en grampones de la microalga sublitoral Macrocystis pyrifera (L.) C. Agardh en el estrecho de Magallanes, Chile. Anales del Instituto de la Patagonia 31:75-86. Punta Arenas.

SALEMME, M. y G. BUJALESKY. 2000. Condiciones para el asentamiento humano litoral entre Cabo San Sebastián y Cabo Peñas (Tierra del Fuego) durante el Holoceno medio. En Desde el País de los Gigantes. Perspectivas arqueológicas en Patagonia II, Universidad Nacional de la Patagonia Austral, Río Gallegos: 519-532.

SCARTASCINI, F. L. Y M. CARDILLO. 2009. Explorando la variabilidad métrica y morfológica de las "Pesas líticas" recuperadas en el sector norte de la costa del golfo San Matías. Arqueometría latinoamericana: Segundo Congreso Argentino y Primero Latinoamericano / Tulio Palacios ...[et.al.]. Buenos Aires. Comisión Nacional de Energía Atómica. (En Prensa).

SCHINDLER, H. 1995. Un informe etnográficos sobre los onas del año 1765. Runa. XXII: 177-185.

STUART, D. E. 1977. Seasonal phases in Ona subsistence, territorial distribution and organization: implications for the archaeological record. For Theory building in archaeology. Pp: 251-283. Lewis Binford. Academic press. New York.

TORRES, J. 2006. Hacia una zooarqueología de los recursos ictiológicos en Tierra del Fuego: Un caso de estudio en contextos arqueológicos selk'nam de bahía Inútil. Actas 
XVI Congreso Nacional de Arqueología Chilena. Tomé. -2007a. El rol de los recursos ictioarqueológicos y las practicas de pesca en las ocupaciones litorales de los grupos selk nam y preselk nam del norte de Tierra del Fuego. Memoria para optar al titulo profesional de arqueólogo. Universidad de Chile, facultad de Ciencias Sociales, Departamento de Antropología.

-2007b. ¿Redes o líneas de pesca?: El problema de la asignación morfofuncional de los pesos líticos y sus implicancias en las tácticas de pesca de los grupos del extremo austral". Magallania 35(1).

VEGA, C. 1995. Cuando el cielo se oscurece (Samán arkachoé). Editorial Atelí, Punta Arenas, Chile.

VENEGAS, C. Y W. SIELFELD. 1998. Catálogo de los vertebrados de la región de Magallanes y Antártica Chilena. Ediciones de la Universidad de Magallanes, Punta Arenas.
WHEELER, A. Y A. JONES.1989. Fishes. Cambridge University Press, Cambridge.

WHITRIDGE, P. 2001. Zen fish: a consideration of the discordance between artefactual and zooarchaeological evidence for Thule Inuit fish use. Journal of Anthropological Archaeology 20(1):3-72.

ZANGRADO, A. F. 2003. Ictioarqueología del canal Beagle, explotación de peces y su implicación en la subsistencia humana. Sociedad Argentina de Antropología, Colección Tesis de Licenciatura. Buenos Aires

ZANGRANDO F., A. TESSONE Y M. VÁZQUEZ. 2008. El uso de espacios marginales en el archipiélago fueguino: implicaciones de la evidencia arqueológica de bahía Valentín. En: Arqueología de Patagonia: una mirada desde el último confín. Editores M. Salemme, F. Santiago, M. Álvarez, E. Piana, M. Vázquez y M.E. Mansur. Editorial Utopías. Ushuaia. En prensa. 